\title{
Land condition monitoring information for reef catchments: a new era
}

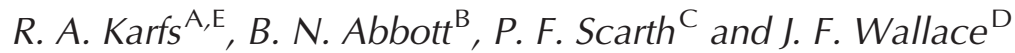 \\ A Department of Primary Industries and Fisheries, PO Box 1085, Townsville, Qld 4810, Australia. \\ ${ }^{\mathrm{B} C S I R O}$ Sustainable Ecosystems, Davies Laboratory, PMB Aitkenvale, Qld 4814, Australia. \\ ${ }^{\mathrm{C}}$ Department of Natural Resources and Water, QCCA Building, 80 Meiers Road, \\ Indooroopilly, Qld 4068, Australia. \\ ${ }^{\mathrm{D} C S I R O}$ Mathematical and Information Sciences, PMB 5, Wembley, WA 6913, Australia. \\ ${ }^{\mathrm{E} C}$ Corresponding author. Email: robert.karfs@dpi.qld.gov.au
}

\begin{abstract}
Land condition monitoring information is required for the strategic management of grazing land and for a better understanding of ecosystem processes. Yet, for policy makers and those land managers whose properties are situated within north-eastern Australia's vast Great Barrier Reef catchments, there has been a general lack of geospatial land condition monitoring information. This paper provides an overview of integrated land monitoring activity in rangeland areas of two major Reef catchments in Queensland: the Burdekin and Fitzroy regions. The project aims were to assemble land condition monitoring datasets that would assist grazing land management and support decision-makers investing public funds; and deliver these data to natural resource management (NRM) community groups, which had been given increased responsibility for delivering local environmental outcomes. We describe the rationale and processes used to produce new land condition monitoring datasets derived from remotely sensed Landsat thematic mapper (TM) and high resolution SPOT 5 satellite imagery and from rapid land condition ground assessment. Specific products include subcatchment groundcover change maps, regional mapping of indicative very poor land condition, and stratified land condition site summaries. Their application, integration, and limitations are discussed. The major innovation is a better understanding of NRM issues with respect to land condition across vast regional areas, and the effective transfer of decision-making capacity to the local level. Likewise, with an increased ability to address policy questions from an evidence-based position, combined with increased cooperation between community, industry and all levels of government, a new era has emerged for decision-makers in rangeland management.
\end{abstract}

Additional keywords: Australian rangelands, Burdekin and Fitzroy regions, land condition monitoring, natural resource management, remote sensing.

\section{Introduction}

Information on land condition and trend is needed to support the sustainable management of natural resources in rangelands. This need is especially pressing for policy makers and those grazing land managers whose properties are situated within river catchments that drain into Australia's Great Barrier Reef(GBR). Failure to manage grazing land sustainably in these catchments has consequences that can affect not only enterprise profitability (e.g. MacLeod et al. 2004), but also the GBR - the world's largest World Heritage Area and biggest tropical marine reserve. The threat to marine habitat from declining water quality entering the GBR caused by increased rates of agricultural nutrients and sediment run-off has been widely reported (e.g. Brodie et al. 2004). It is recognised that improving land condition and increasing groundcover on grazing land can prevent excessive amounts of sediments entering streams and rivers (Fentie et al. 2006). However, there has been little definitive information on where land condition is improving or declining in rangelands lying directly upstream of the GBR in the Burdekin and the Fitzroy regions.

Knowledge of where and when changes in vegetation have occurred is fundamental to monitoring grazing land and management impacts in rangelands (Wallace et al. 2006). In Australia, different site-based land condition monitoring programs have been run by State and Territory agencies (Bastin et al. 2009). Repeated ground measurements of land condition variables including cover and species composition provide data which can be aggregated to quantify regional trends (e.g. Watson et al. 2007), or benchmark condition (Friedel et al. 2000). Conventional site data are important for scientific understanding of complex ecological processes in rangelands. Yet, they are extremely sparse in space and time to adequately represent contemporaneous changes in the landscape at multiple geographical scales. Conventional site-based land condition monitoring datasets are generally too broad for application at the property scale. Nor are detailed property scale site aggregates 
(e.g. StockTake - Aisthorpe and Paton 2004) suitable for developing regional outlooks. Methods for rapid ground-based monitoring via vehicular traverse have been deployed in Australian rangelands for some time (e.g. Payne et al. 1998; Hassett et al. 2000). Although providing a useful set of data normally to complement other land condition monitoring data, this form of monitoring can become, depending on how 'rapid' the assessment is, resource intensive (although less so than scientific site measurements), and is generally restricted to the road corridor. The problems of inadequate spatial coverage and temporal variability in ground sites for identifying specific land condition issues at multiple scales can be addressed by the use of time-series remote sensing data.

Remote sensing provides the quantitative means to consistently identify temporal changes in rangeland vegetation at multiple spatial scales; from paddock and property scale to catchment and continental scale. A large body of work has been undertaken in Australian rangelands, over 25 years, studying the relationships between reflected surface electromagnetic radiation (in the visible, near-infrared, short-wave, and thermal infrared regions of the spectrum) recorded by Landsat Earth observation satellites, and vegetation cover as measured at field sites (e.g. Graetz and Gentle 1982; Pech et al. 1986; Graetz et al. 1988; Pickup et al. 1993; Wallace et al. 1994; Bastin et al. 1996; Caccetta et al. 2000; Taube 2000; Karfs 2002; Richards and Furby 2002; Danaher et al. 2004; Scarth et al. 2006; Jafari et al. 2007; Ludwig et al. 2007a; Lawes and Wallace 2008). The capacity to detect and monitor relative differences in vegetation cover has largely been accomplished, and has been implemented in operational programs in Australia using Landsat imagery (see Wallace et al. 2006). Land condition statements relying on the analysis and interpretation of the patterns of groundcover change can be made and applied over landscapes (e.g. Karfs 2002), thus, providing consistent and spatially complete information of an important attribute of land condition (e.g. Dube et al. 1999; Booth and Tueller 2003). However, the ability to characterise species composition another important attribute of land condition - from remote sensing over extensive heterogeneous rangeland environments is an unresolved challenge (Wallace and Campbell 1998; Ludwig et al. 2000; Okin et al. 2001; Mundt et al. 2006).

Landsat imagery provides a long-term archive at management-relevant scales (site, paddock, region), which places emphasis on the multiple scale capabilities of remote sensed information. In its 'Plan for a USA National Land Imaging Program', the United States Office of Science and Technology Policy assures the future of the Landsat-class program (OSTP 2007). A précis from this important document justifying the need for medium resolution imagery is stated as:

'Contemporary technologies preclude use of high resolution remote sensing data $(<5 \mathrm{~m})$ on a 'wide area of coverage' basis due to extremely high data volumes and the capacity of current communication systems. Similarly, very low-resolution systems $(>120 \mathrm{~m})$ do not capture a sufficient level of detail to detect human-scale features on the Earth. Medium resolution systems $(5-120 \mathrm{~m})$ such as Landsat fill a niche designed for detecting seasonal changes that best enables assessment of local and regional impacts. The information derived from such systems complements data obtained from other sources including airborne platforms and ground measurements and observations'.

The Landsat satellite image archive contains repetitive, medium spatial resolution and multispectral measurements extending over $30+$ years ( 25 years for Landsat TM), that are unmatched in quality, detail and coverage (Williams et al. 2006). Landsat imagery is suited to monitoring the vast areas of Australian rangelands where underlying trends in land condition affected by climatic variability may operate over periods of a decade or more (Pickup et al. 1998). For any modern rangeland monitoring system, there is now little doubt of the need for the extrapolative capacity of remote sensing technology combined with ground measurements and observations (e.g. West 2003; Washington-Allen et al. 2006). However, there are still major challenges associated with the task of mapping land condition in rangelands, with consequences for the development of monitoring systems. These challenges include system efficiencies in conducting monitoring activities over vast areas, separating management from natural seasonal effects, and deriving universal condition classes (Bastin and Ludwig 2006). As a result of these challenges, there is still no definitive map of rangeland condition across the grazing lands of Australia, even though monitoring methods and analyses are continually improving towards realising this goal (see Bastin and the ACRIS Management Committee 2008).

The ABCD land condition framework by Chilcott et al. (2003) has provided differentiation between grazing land condition classes that has gained wide acceptance in Queensland. The framework was constructed from existing knowledge of grazing land ecology and relies on data from long-term grazing trials (e.g. Ash et al. 2002; O'Reagain et al. 2003). Explicit in the definition of good condition is the maintenance of ecosystem processes such as water and nutrient cycling, resulting in stable pasture production responses across seasons relative to the livestock carrying capacity. The target of the ABCD land condition framework is grazing land use and hence the measure is defined as 'The ability of land to respond to rain and produce useful forage'. Understanding land condition is, thus, a critical component in understanding the productive potential of the land, and a basis for deciding when to alter stocking rates, introduce spelling practices or modify infrastructure to minimise damage in degraded areas.

\section{New policy and collaborative framework}

In the early 2000s, new natural resource management (NRM) environmental policy was initiated in Australia. As a result, some of the decision-making responsibility and accountability for the environment was shifted from centralist bodies to regional community catchment management bodies. Through this cooperative federalism approach, it was anticipated that in building regional capacity, improved value for money and the determination of strategic investments locally will achieve better environmental outcomes (NRMMC 2002). Similarly, a need for land condition monitoring information in rangelands at multiple scales was identified as a priority investment by 
NRM regional bodies - Burdekin Dry Tropics (BDT) and the Fitzroy Basin Association (FBA); for supporting resource condition evaluation and target-setting, and for helping improve grazing land management. The imperative to improve water quality in the GBR was more recently brought into focus through a commitment by the Australian Government of an additional Au\$200 M under its 'Reef Rescue Plan'.

This paper presents results from land condition monitoring projects operating from 2006-08 in the two largest GBR catchments, the Burdekin and the Fitzroy. The aim was to produce land condition monitoring information aimed at management and policy priorities in the region, and to deliver these through regional bodies. We describe products derived from remote sensing and ground assessment datasets that include subcatchment groundcover change maps, regional mapping of indicative very poor land condition, and regional 'windscreen' rapid condition assessment. Their integration and their application, and limitations are also discussed in what is certainly a new era emerging for NRM decision-makers in rangeland management.

\section{Materials and methods}

\section{Project Area}

The project area extends from $144.13^{\circ} \mathrm{E}, 18.05^{\circ} \mathrm{S}$ to $151.58^{\circ} \mathrm{E}$, $26.50^{\circ} \mathrm{S}$ (Fig. 1), incorporating the Burdekin and the Fitzroy, which are the two largest river catchments that drain into the GBR (catchment areas are 133500 and $142300 \mathrm{~km}^{2}$, respectively). These catchments deliver around one quarter of the freshwater flow to the Reef, from approximately one third of the total Reef catchment area. Combined population in the two regions is over 400000 (Australian Bureau of Statistics 2008; the majority living in the coastal cities of Townsville and Rockhampton). The climate is considered tropical to subtropical humid to semi arid. Most rainfall occurs in the warmer months of the tropical wet season (December-April), but rainfall patterns can be highly variable and followed by periods of extended drought. In general, inland parts of the catchments receive an average annual rainfall of between 400 and $600 \mathrm{~mm}$, which increases towards the coast $(1000 \mathrm{~mm})$ with maximum precipitation at the northernmost coastal ranges $(1800 \mathrm{~mm})$.

Cattle grazing is the dominant land use - comprising $90 \%$ of the land area of the Burdekin and the Fitzroy (Queensland Land Use Mapping Program QLUMP 2004 product, see Witte et al. 2006). Queensland's beef industry contributes more than one third of the total value of Queensland's primary industry commodities and is the largest agricultural commodity in the State; gross value production (GVP) at the farm gate was estimated at Au\$3.4 billion in 2007-08 (DPI\&F 2008). Although specific production values are difficult to quantify, the Burdekin and Fitzroy catchments are significant cattle producing regions (e.g. the Central Queensland region, which includes the Fitzroy, produced $23 \%$ of the State output in cattle and calves in 2005-06). Continuation of this economic success requires maintenance of grazing land in good condition (i.e. a capacity to produce useful forage), to grow and breed livestock, and to minimise impacts on natural resources that drain into the GBR. Over the past decades, extensive clearing of Brigalow in the Fitzroy has given way to large tracts of grazing on sown

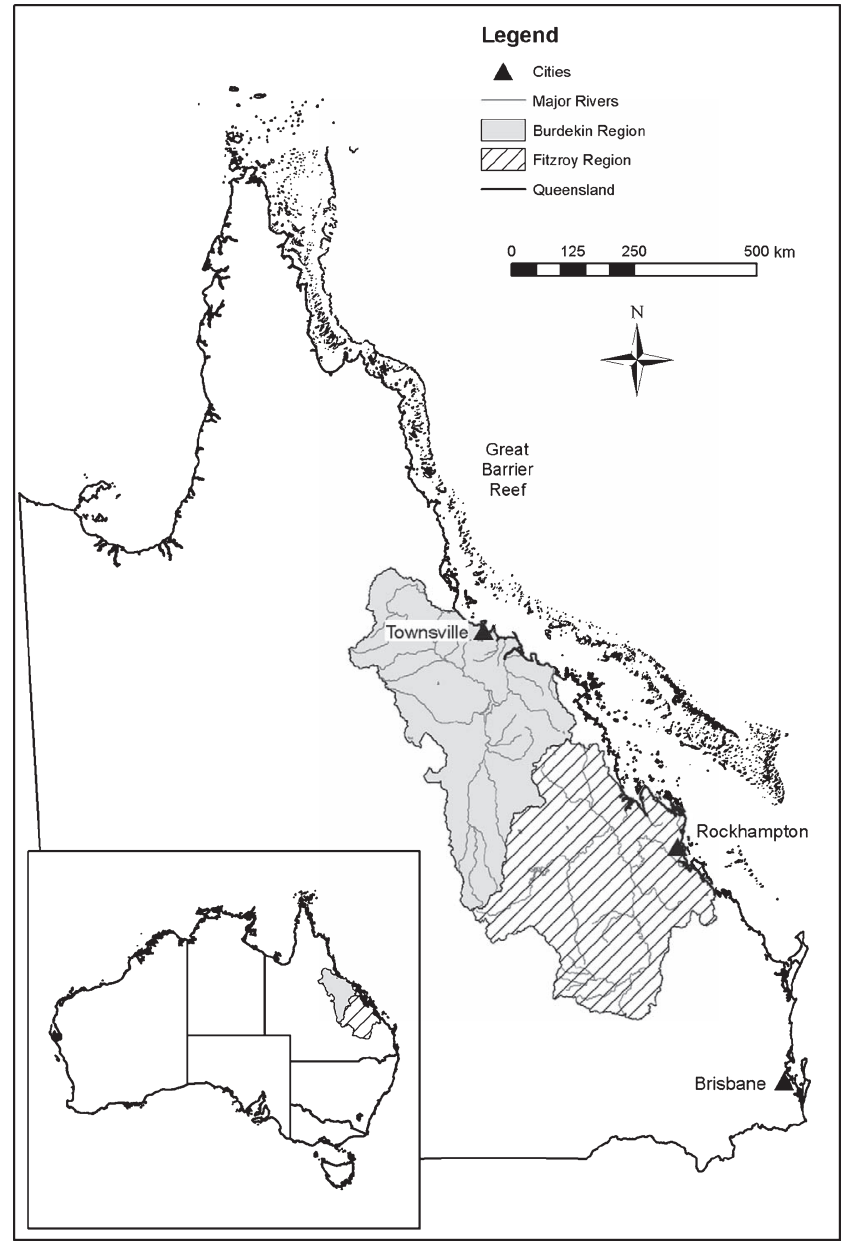

Fig. 1. Location of the project areas in the State of Queensland.

pastures and broad acre cropping. Clearing has occurred to a lesser extent in the Burdekin; the northern half of the region is largely managed as grazed remnant vegetation, and the coastal zone of the Lower Burdekin delta is one of Australia's largest sugar producing regions.

\section{Landsat time-series remote sensing data}

Landsat TM and ETM+ satellite images were acquired during the mid to late dry season (e.g. July-November). The images were least cloud-affected at this time, and the regional green up of ground vegetation had generally passed; minimising spectral differences on annual time-step imagery while maximising spectral contrast with tree overstorey. The Landsat TM data were calibrated by replacing the on-board radiometric calibration with vicarious calibration based on a model of the lifetime response of the sensor (De Vries et al. 2004). Pre-flight coefficients were used to calibrate the Landsat-7 ETM+ (Enhanced Thematic Mapper Plus sensor onboard Landsat-7) data to radiance (NASA 2004). All imagery was then corrected for bidirectional reflectance variations of the atmosphere and land surface (Danaher 2002), and subsequently incorporated into the existing SLATS database (Statewide Landcover and Tree 
Study - www.nrm.qld.gov.au/slats/, Accessed 7 August 2008). Landsat images were resampled to $25 \mathrm{~m}$ (nominal scale $1: 100000)$ and constructed into annual regional mosaics spanning the period from 1986 to 2006. Fourteen adjoining Landsat scenes were needed to cover the Burdekin and a further 16 scenes required for the Fitzroy.

Estimates of groundcover using Landsat data transformed into the ground cover index (GCI), which originates from the research by Taube (2000), was a fundamental output from the project. The GCI is based on multiple regression statistics from Landsat TM bands applied to the corrected SLATS image archive. Groundcover was defined as total organic soil surface cover, including senescent and green grasses and forbs, grass and tree litter and cryptogams. Its complement, 'bare ground', includes bare soil and rock. Data from over 400 statewide ground-measured sites were used to calibrate the GCI used in the project (Scarth et al. 2006). All GCI values shown here have been rescaled so the pixel values represent groundcover between 0 and $100 \%$. In addition to the GCI, the foliage projective cover (FPC) index by Danaher et al. (2004), developed as part of related research, was used to identify variable densities of woody vegetation for targeting the groundcover assessments. The calibration data suggests that GCI can be applied across a range of soil units, like the FPC Index, so that stratification of disparate land types is not required. It is noted that the GCI provides estimates of groundcover, which is approximate at any single date. The root mean square (RMS) error in the regression is approximately $\pm 13 \%$ (Scarth et al. 2006), which is considerable, especially at low cover levels.

Where dense woody vegetation occurs, there are further limitations to the application and interpretation of the GCI. Owing to the influence of overstorey on aggregate pixel reflectance values, accurate groundcover estimates may not be possible in densely wooded landscapes. Scarth et al. (2006) recommend the use of the GCI only in areas having woody FPC $\leq 20 \%\left(\sim 8 \mathrm{~m}^{2} \mathrm{ha}^{-1}\right.$ basal area or $40 \%$ canopy cover $)$. The project area under a grazing land use and with a woody FPC $\leq 20 \%$ was $\sim 70 \%$ of the Burdekin and $58 \%$ of Fitzroy.

\section{Remote identification of low cover and bare ground - candidate D-condition}

The ABCD land condition framework by Chilcott et al. (2003) has four classes that are based on the density of $3 \mathrm{P}$ grasses (perennial, palatable and productive grasses), soil condition, presence of weed species and woody density (Table 1). The extent and location of very poor condition or D-condition lands in the Burdekin and Fitzroy was unknown, and these areas were a identified as a priority in terms of erosion and remediation decisions by the NRM Regional Bodies. An opportunity was recognised for using remote sensing to identify areas described under the first two points of D-condition, i.e. 'a general lack of perennial grasses or forbs; severe erosion and large bare areas'. We refer herein to these areas as 'candidate D-condition'. Remote identification of D-condition areas dominated by weed cover or thickets of woody plants at the regional scale was considered unlikely, although mapping active weed invasion has recently been accomplished through remotely monitoring distinctive weed cover increases (Lawes and Wallace 2008).
Table 1. ABCD condition classes of Chilcott et al. (2003)

\begin{tabular}{|c|c|}
\hline \multicolumn{2}{|r|}{$\mathrm{ABCD}$ condition class and description } \\
\hline A (Good) & $\begin{array}{l}\text { High density and coverage of } 3 \mathrm{P} \text { grasses and little } \\
\text { bare ground } \\
\text { High organic matter }\end{array}$ \\
\hline B (Fair) & $\begin{array}{l}\text { Moderate density and coverage of } 3 \mathrm{P} \text { grasses } \\
\text { Moderate organic matter }\end{array}$ \\
\hline C (Poor) & $\begin{array}{l}\text { Few 3P grasses } \\
\text { Some erosion } \\
\text { Higher numbers of annuals }\end{array}$ \\
\hline D (Very poor) & $\begin{array}{l}\text { General lack of perennial grasses or forbs } \\
\text { Severe erosion and large bare areas } \\
\text { Higher numbers of weeds } \\
\text { Thickets of woody plants covering most of the area }\end{array}$ \\
\hline
\end{tabular}

For identifying low cover and bare ground two independent remote sensing datasets were used: first, an 11-year GCI Landsat TM time-series from 1996-2006; second, high resolution SPOT 5 Panchromatic (PAN) data (nominal 1:10000 scale, $2.5 \mathrm{~m}$ pixels). Some 72 SPOT 5 scenes were captured over a 2-year period from 2005 to 2007 as weather permitted to create a notional 'single date' regional mosaic dataset. These data were available as part of a multi-agency acquisition to use satellite imagery for general mapping purposes and assisting in the identification of rural infrastructure (see www.bdtnrm.org.au/ mapsandimages/aboutspot5imagery.html, Accessed 1 March 2009). Areas with woody FPC $>20 \%$, and areas of towns, large water bodies and non-grazing land use were removed from the analysis [using SLATS 1988-2005 FPC product and the Queensland Land Use Mapping Project (QLUMP) 2004 product]. Coastal agriculture was also excluded; resulting in an $82421 \mathrm{~km}^{2}$ area of the Burdekin Rangelands assessed using remote sensing (Fig. 2).

Given the known errors in the spectral-cover relationships, remote sensing of heterogeneous rangeland environments separates low groundcover from bare ground rather imprecisely. Combining high resolution imagery with time-series cover information improves capacity. For example, in areas with a significant proportion of trees but at a density of $\leq 20 \%$ FPC, TM sensors record a spectrally mixed cover signal in pixels with variable components of leaf overstorey, groundcover and soil. Thus, some bare areas in treed environments may go undetected using Landsat TM data. The higher resolution multispectral SPOT 5 data at $10 \mathrm{~m}$ resolution (simultaneously captured with PAN) unfortunately was affected by seasonal differences. This imagery had sharply contrasting radiometric values across some adjoining scenes, resulting from data acquisition lasting over a 2-year period, and was of limited value for cover analysis without large amounts of image processing.

The high resolution of the SPOT $2.5 \mathrm{~m}$ PAN data generally overcame the pixel mixing problem, because even with $2.5 \mathrm{~m}$ pixels there can be some spectral mixing, although greatly reduced from that expected for $25 \mathrm{~m}$ pixels, and, to a large extent, the seasonal effects inherent to the $10 \mathrm{~m}$ SPOT multispectral data. At high resolution, tree canopy could generally be discriminated and small areas of bare/low groundcover identified. However, the PAN imagery would not detect areas normally lacking perennial grasses and forbs (and 


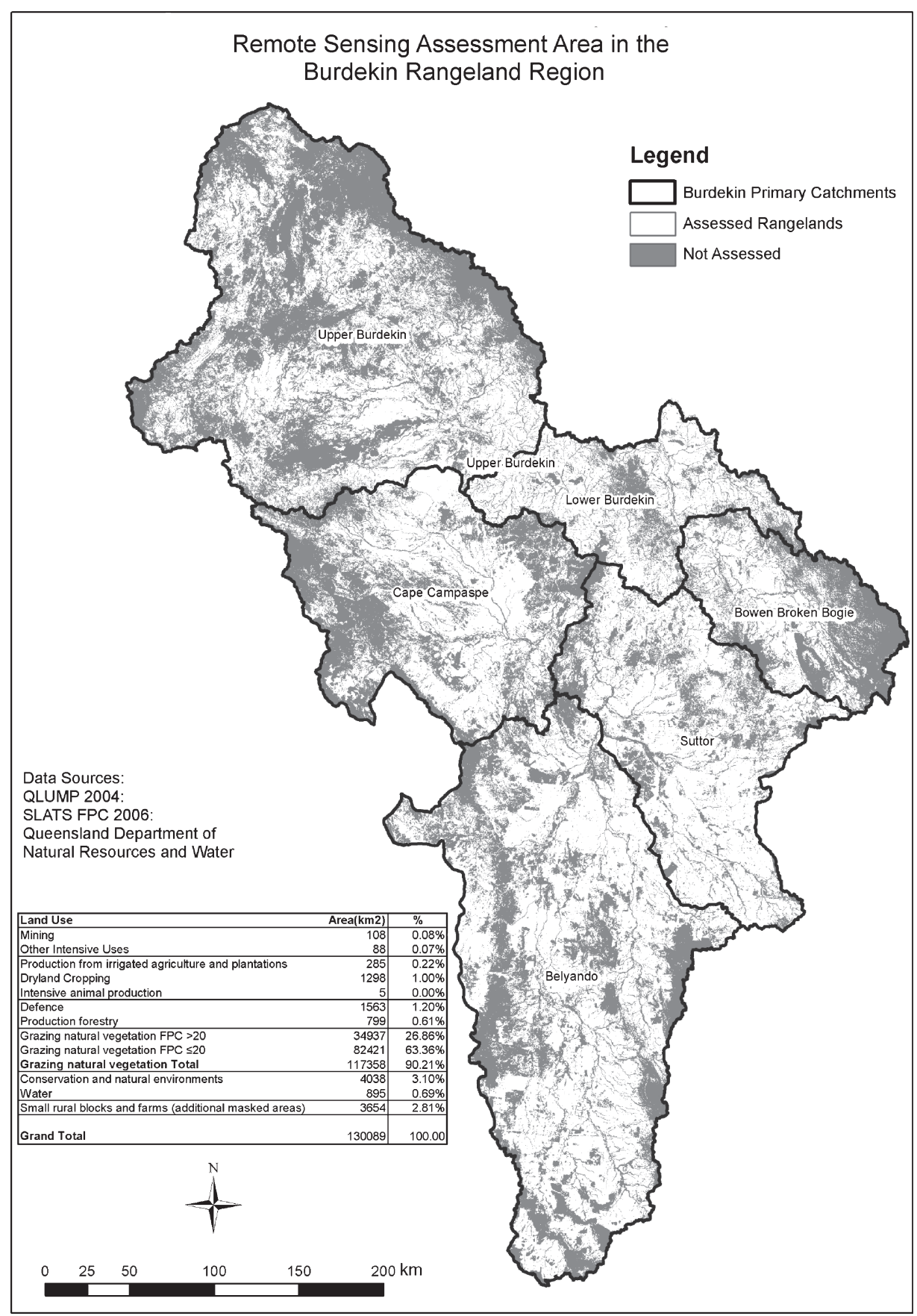

Fig. 2. The area of Burdekin rangelands assessed using remote sensing methods that had grazing land use and woody foliage projective cover $\leq 20 \%$ ( $82421 \mathrm{~km}^{2}$ or $70 \%$ of Burdekin Rangeland grazing lands).

in D-condition) if they were covered with litter and annual grass species at the time of image capture (e.g. because of favourable rainfall). Similarly, perennial grasslands temporarily defoliated at the time of image capture (and not in D-condition), due to a fire or a heavy grazing defoliation event, may be misclassified as low cover or bare. By integrating the GCI timeseries of Landsat TM with the high spatial resolution of SPOT PAN, we reduced several limitations for identifying recurrent low groundcover and bare ground from remote sensing - as a surrogate of D-condition.

In the Burdekin region, we considered rangeland to be degraded if it had less than $40 \%$ groundcover as assessed in the field. This cut-off was based on the field data by McIvor et al. (1995), Roth (2004), Abbott and Corfield (2006), and other unpublished data. Land cover change analysis (Karfs et al. 2000), for summarising GCI mean and trend values, provided a 
matrix of GCI values for the 11-year period (1995-2006) (Table 2). Mean GCI was stratified into three classes: high $(>60 \%)$, medium $(40-60 \%)$ and low $(<40 \%)$. Each of these classes was further stratified into a trend classification of increasing trend, stable trend and decreasing trend. For the SPOT 5 PAN imagery, thresholds were assigned to pixel brightness by means of simple sequential classification of values (Ludwig et al. 2000) to extract areas thought to represent very low cover or bare ground for each scene. Actual threshold values for candidate $\mathrm{D}$-condition varied from scene to scene due to residual seasonal differences, but generally thresholds were set within the upper $20 \%$ of radiance values for each scene. Hence, remotely sensed candidate D-condition was considered as either one of three classes (Table 3): acute single-date (SPOT 5 PAN), persistent multi-date (Landsat TM low mean GCI) and marginal multi-date (Landsat TM medium mean GCI and decreasing trend). The marginal multi-date class was included to identify areas where annual groundcover was abundant, but lacking in 3P grasses, which in favourable seasons could have GCI values that exceeded the $40 \%$ threshold. Segregating natural features such as rock outcrop from the D-condition mapping was not attempted; however, such features were presumed to be only a minor component of the remote candidate D-condition assessment.

A preliminary D-condition map product was groundtruthed at sites spread across the Burdekin over a 2-week period in September 2007 using PATCHKEY methods. PATCHKEY (Corfield et al. 2006) is a quantitative ground-based method to assess land condition using thresholds within the key groundcover vegetation drivers of the $\mathrm{ABCD}$ framework, and key landscape function drivers at a patch level (Tongway and Hindley 2004). Prior to groundtruthing surveys, cover assessment calibrations were conducted to achieve a relationship between the assessor and actual groundcover. Vertical digital photographs of 20 separate $1-\mathrm{m}^{2}$ quadrats on a grazier property located west of Townsville were classified into cover and bare ground using automated and manual classification techniques. For the regional groundtruth survey,

Table 2. Matrix of Landsat ground cover index (GCI) trend and mean $\mathrm{X}$, GCI values most likely to be low cover or bare ground representing candidate $\mathrm{D}$-condition; $\mathrm{O}, \mathrm{GCI}$ values unlikely to be low cover or bare ground

GCI Trend

Increasing Stable Decreasing

\begin{tabular}{lclll}
\hline Mean GCI & High $>60 \%$ & $\mathrm{O}$ & $\mathrm{O}$ & $\mathrm{O}$ \\
& Medium $40-60 \%$ & $\mathrm{O}$ & $\mathrm{O}$ & $\mathrm{X}$ \\
& Low $<40 \%$ & $\mathrm{X}$ & $\mathrm{X}$ & $\mathrm{X}$ \\
\hline
\end{tabular}

Table 3. Candidate D-condition classes identified from remotely sensed data

\begin{tabular}{ll}
\hline Class & Description \\
\hline Acute single-date & SPOT 5 PAN low cover and bare ground \\
Persistent multi-date & Landsat TM - low 11-year mean GCI of $<40 \%$ \\
Marginal multi-date & Landsat TM - medium 11-year mean \\
& GCI of 40-60\% and decreasing trend \\
\hline
\end{tabular}

25 prospective site locations representing different groundcover levels were selected from the 2006 GCI dataset. Upon arrival in the field seven sites were deemed inappropriate because they supported other land use types (house yards, cattle yards, borrow pits, mines) or they were inaccessible. For the remaining 18 sites three transects per site were measured. Transects were 100 or $200 \mathrm{~m}$ in length depending on features of interest with PATCHKEY measurements spatially referenced using differential GPS to within an error of $1.5 \mathrm{~m}$.

\section{Rapid condition assessment (RCA)}

Rapid condition assessment (RCA) refers to the subjective visual appraisal of $\mathrm{ABCD}$ land condition at a geo-referenced location while travelling in a moving vehicle (i.e. 'windscreen assessments'). Its purpose is to build a regional picture of land condition. RCA sites are assessed literally within seconds, but can be revisited if further investigation is required. Advantages of this form of land condition monitoring are the ability to capture large ground datasets quickly, extending the coverage of condition ratings. Disadvantages are a bias along road corridors that may result in an incomplete sample of some catchments or land types, and the need for moderately high levels of local landscape understanding by observers. RCA is not intended to replace intensive field measurements that are needed for understanding the ecology of rangeland systems. Rather RCA aims to 'fill in the gaps' between scientific sites that have poor spatial representation.

The RCA approach was designed after Hassett et al. (2000), Karfs (2002) and Karfs and Saunders (2004). RCA was targeted for periods when the ground vegetation was mostly senescent during northern Australia's dry season. At this time of year, it is easier to distinguish perennial grass from annual species and bare soil; access along unsealed roads is generally good; and these months correspond to acquisition of Landsat satellite data for calibrating GCI. RCA was conducted in all grazing lands, regardless of woody FPC density. The data collection system comprised of a Garmin Map 60c GPS (or similar) connected to a laptop running Fugawi v4.0 (Fugawi 2007) or CIGS (see Hassett et al. 2000) navigational software. Positional accuracy of the GPS was $<15 \mathrm{~m}, 95 \%$ typical (Garmin 2005). On-screen background rasters including topographic maps, land use, FPC, Landsat GCI time-series summary images, and road layers were used at various times for helping to anticipate changes in the landscape en route. The RCA procedure is a 'free' survey (see Gunn et al. 1988), commonly used in Australian soil science as opposed to a grid or random survey. Accordingly, sites were recorded as changes in land condition or land type were encountered or as points along extended intervals of similar landscape character.

RCA sites were restricted to the landscape that was visible adjacent to the road corridor, along main public roads and along some property tracks. Site frequency depended upon the speed in which the vehicle travelled ranging from $30-100 \mathrm{~km} \mathrm{~h}^{-1}$. Generally, there was one site recorded for every $1-2 \mathrm{~km}$ travelled. At least two staff members were in the vehicle - one driving and one recording - with one having familiarity with the region assessed. The land condition monitoring assessments were made of uniform areas, out $75-125 \mathrm{~m}$ to the side of the 
road nominated by observers, focusing on the average condition of a 1-2 ha area. Land condition of the immediate road corridor was avoided, unless otherwise noted, to minimise confusion with the adjoining paddock that was often separated from the road by a fence (in terms of differences in disturbance, pasture type and weeds). Frequent stopping for roadside inspections was made as a means for assessors to confirm condition classes, although no formal measurements were undertaken to calibrate the RCA assessments. Roadside photographs were taken at selected sites and geo-referenced, providing visual evidence in support of the ABCD condition class assigned. In addition to the $\mathrm{ABCD}$ rating, multiple land condition attributes were recorded to inform why a particular rating was given. These attributes included: percentage groundcover; dominant groundcover - perennial, annual or litter; dominant species; presence of erosion and/or weeds - their severity and type; woody density - estimated in six classes from isolated clumps to dense forest (see McDonald et al. 1990); and presence of fire. Grazing intensity classes - none, light, moderate, heavy and very heavy - were also recorded, as well as space provided for commentary to further describe features and situations that were encountered. Attribute classes were devised to assist observer decision-making, for example, estimates of percentage groundcover for all organic material (grass, herbs and litter) $<2 \mathrm{~m}$ tall was divided into intuitive classes that could be readily visualised while travelling in a moving vehicle, i.e. $0-5,6-20$, $21-50,51-80$, and $81-100 \%$. Supplementary to the land condition assessment, 'observational sites' were recorded of features of interest along transect (e.g. waters, cattle supplement points, cropping areas, forest, etc.), providing a continuous record of information across all land uses. Once RCA data were cleaned, collated and standardised in Microsoft Excel, the data were imported into a GIS and stratified into spatially meaningful units for analysis.

\section{Results}

\section{GCl at the subcatchment scale}

GCI data were provided to the NRM regional bodies in standard GIS formats and at a range of scales. Since the region-wide Landsat GCI time-series dataset (1986-2006) had a large file format (i.e. 10 gigabytes), the GCI data were also supplied as annual dates trimmed to the subcatchment scale to facilitate its use. For example, maps of the Fox Creek subcatchment $\left(3205 \mathrm{~km}^{2}\right)$ within the Belyando Basin of the Burdekin show an increase in GCI values (as surrogates for groundcover) between 2004 and 2006 (Fig. 3). The GCI data in this example (i.e. Landsat images) were acquired on nearly the same date, 2 years apart, during the mid-dry season: 11 August 2004 and 2 August 2006, respectively. Although these maps provide a spatial view of groundcover change between two dates, histograms representations of GCI pixel values provide information which to quantify the distribution of GCI values within the subcatchment (Fig. 3). In 2004, the GCI mean value for all pixels in the subcatchment was $55 \%$, with $20 \%$ of the subcatchment having an estimated groundcover of less than $40 \%$. In 2006 , the mean value increased to $71 \%$ while only $7 \%$ of the subcatchment had an estimated groundcover of less than $40 \%$. Assessing these values over the entire sequence of
Landsat dates provides historical context (Fig. 4). The 2004 value compares with low GCI values recorded during severe drought from 1992-96, but the 2006 value is near the subcatchment average calculated for the 21-year period (1986-2006).

Rainfall statistics provide a further perspective. For example, annual rainfall totals were calculated from daily interpolated rainfall surfaces (Jeffrey et al. 2001) in the Fox Creek subcatchment over the 12-month period from 1 July to 30 June, to capture the cumulative effect of the northern Australian wet season. The totals for 2004, 2005 and 2006 were 421, 453 and $457 \mathrm{~mm}$, respectively. The 21-year average from 1986 to 2006 was $464 \mathrm{~mm}$. Typically, the majority of wet season rainfall arrives in the months of January, February and March and with it a summer dominant growing season. However, plant growth patterns can be highly variable depending on location, combinations of summer and winter rainfall, solar radiation, nitrogen availability and species type (McKeon et al. 1998). Hence, although annual rainfall in 2004 was just 8\% less than that received in 2005 and 2006, a combination of other factors may have resulted in the mean GCI value for the Fox Creek catchment being 22\% lower in 2004 compared with 2005 and 2006.

\section{Ground validation of candidate D-condition in the Burdekin}

To test relationships of GCI with ground-estimated data, a twostage approach was applied to convert visual groundcover estimates to objective cover (e.g. Murphy and Lodge 2002). First, visual groundcover estimates completed by assessors on test plots were calibrated to actual plot cover using curvilinear regression (Fig. 5). Second, the equation for the fitted line was applied to objective observer field measurements from 2007 in validating the GCI against PATCHKEY condition variables of groundcover and landscape function. Average PATCHKEY groundcover values were regressed against corresponding Landsat GCI pixel values across the 18 sites (Fig. 6). This relationship was encouraging in that the GCI averaged across pixels was generally representing groundcover at the larger patch scale. The 1-year gap between the imagery and the groundtruthing introduces uncertainty however, and variation about the fitted line illustrates the scale of the errors in the quantitative estimates of groundcover, which is similar to those reported elsewhere (e.g. Pickup et al. 2000). A much better fit would be expected using 2007 GCI data regressed against the 2007 field data. The high resolution of $2.5 \mathrm{~m}$ SPOT PAN imagery allowed manual checking of the acute single-date classification for accuracy.

Based on these validation results, a map depicting remote sensing candidate D-condition classifications was produced for the area of Burdekin rangelands under a grazing land use with a woody cover $\leq 20 \%$ FPC (Fig. 7). For the rangelands assessed $\left(82421 \mathrm{~km}^{2}\right)$ the combined percentage of acute single-date $(1.12 \%)$ and persistent multi-date $(2.17 \%)$ indicate a general lower limit of $3.3 \%$ candidate D-condition in the Burdekin (Table 4). This 3.3\% plus marginal multi-date areas (i.e. could be $\mathrm{C}$-condition or D-condition) of $4.6 \%$ indicates an upper limit of $7.9 \%$. Therefore, the proportion of candidate D-condition 

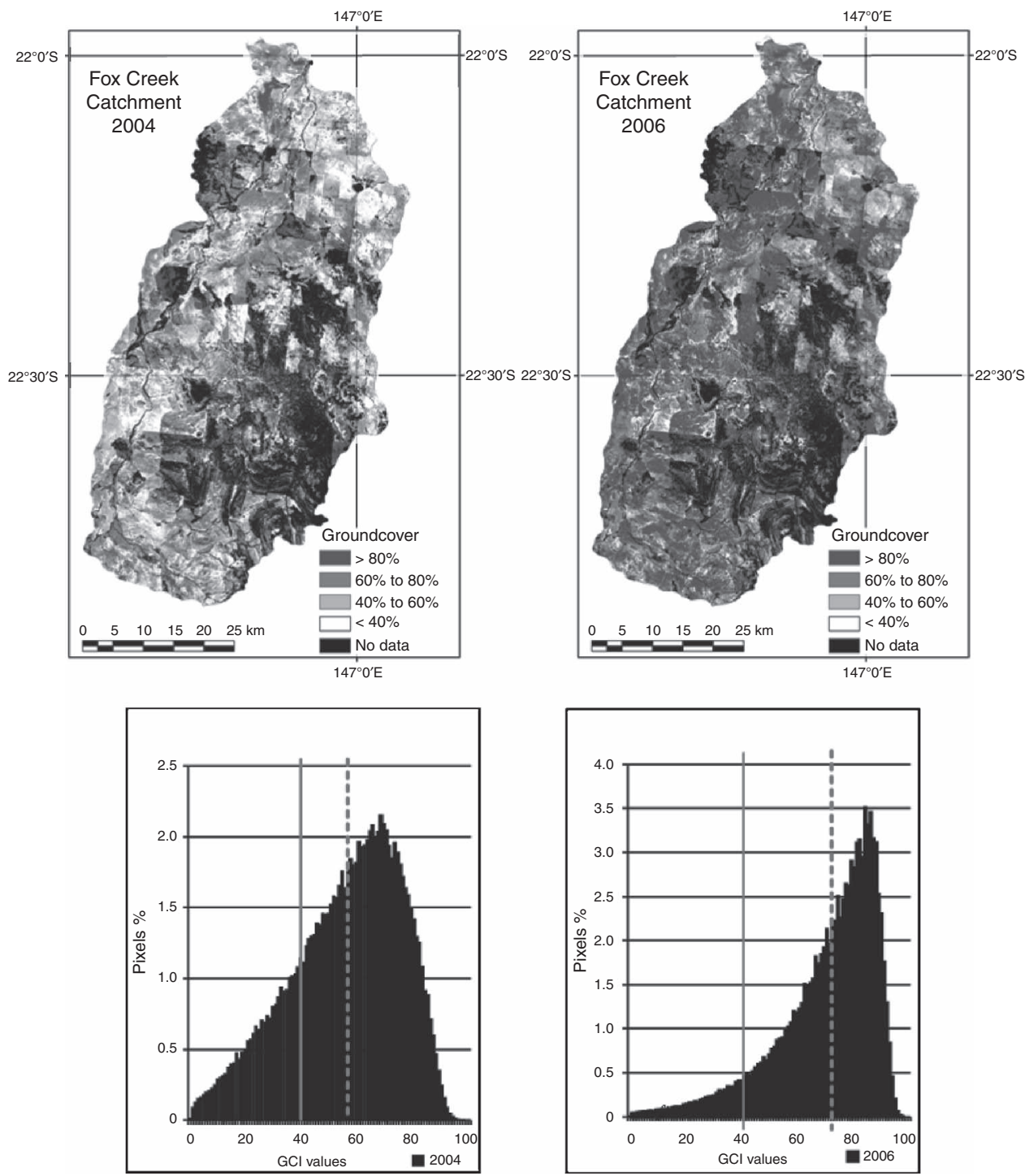

Fig. 3. Fox Creek sub-catchment Burdekin region: change in Ground Cover Index (GCI) 2004 (left) to 2006 (right). High GCI depicted in darker shades; low GCI white to lighter shades. Areas with woody foliage projective cover $>20 \%$ masked in black. GCI sub-catchment histograms show the percentage of sub-catchment area (in pixels) having a particular level of groundcover indicated by GCI values from $0 \%$ to $100 \%$ : solid line $=40 \%$ GCI value; dashed line $=$ mean GCI value for the specified year. A generally higher level of sub-catchment groundcover is represented as a right skewed histogram distribution (towards the higher GCI values).

for the rangelands assessed in the Burdekin was estimated between 3.3 and $7.9 \%$.

\section{RCA distributions and comparison with candidate D-condition}

A total of 10268 RCA sites were assessed across the Burdekin and Fitzroy over consecutive years from 2004 to 2007 (Fig. 8), with a variable number of sites surveyed in these catchments over the 4 years (Table 5 ). The progressive increase in sites assessed from 2004 onwards was due to migrating from Fugawi to CIGS navigational software in 2006, and the addition of a second assessment team in the Fitzroy in 2007. Approximately $13390 \mathrm{~km}$ was travelled during the 4-year period. A total of 17 surveys involving 10 different staff members were conducted. The average period for a survey was 4 days. The number of RCA sites collected daily was typically between 100 and 300 while travelling $300-500 \mathrm{~km}$ by road. The corresponding Author was part of the assessment team in over $57 \%$ of the 10268 sites. Training in RCA protocols were given to new team members before independent assessments. Overall, from 2004 to 2007, the percentage of D-condition sites was $6 \%$ for the Burdekin and $2 \%$ for the Fitzroy (Fig. 9). 


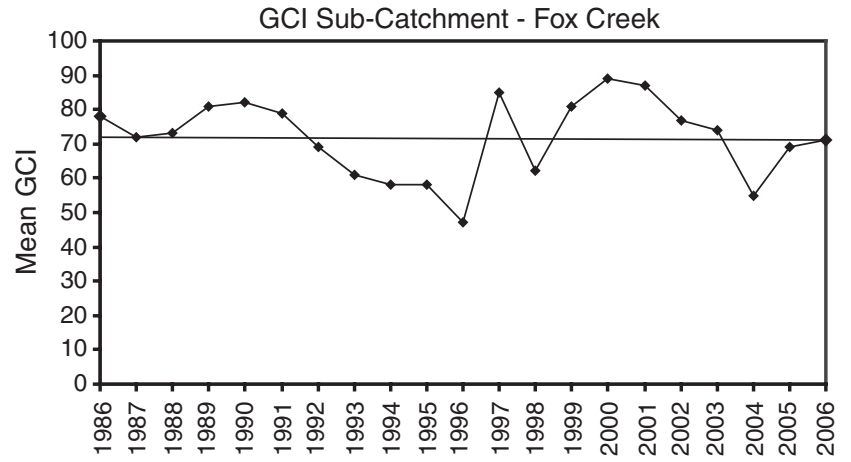

Fig. 4. Time trace of mean Ground Cover Index (GCI) values for the Fox Creek Catchment (1986-2006). The 21-year average GCI value of 72 $($ s.e. $=2.5)$ is indicated by the solid line.

Regression curve between estimated and measured groundcover

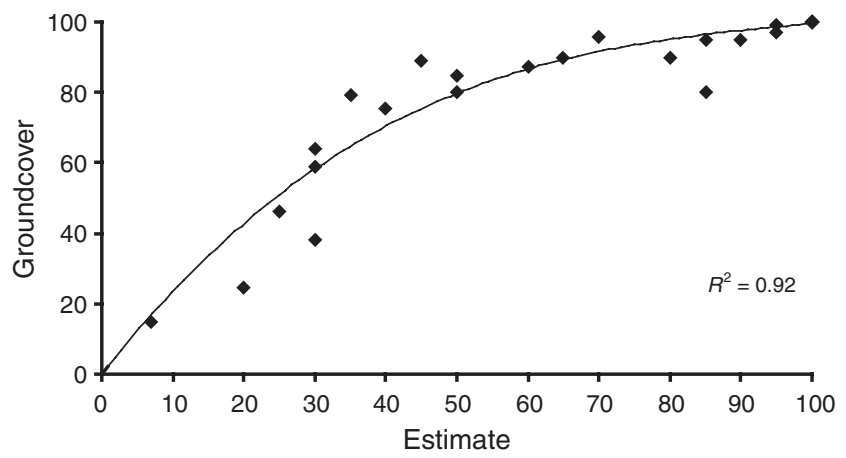

Fig. 5. Relationship between measured groundcover and estimated groundcover of $1 \mathrm{~m}^{2}$ quadrats used in the calibration process (s.e. $=9.2$ ).

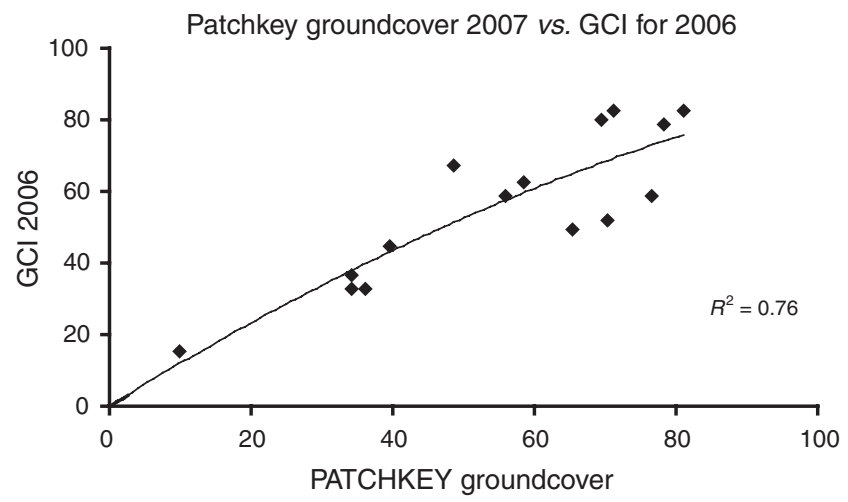

Fig. 6. Relationship between measured groundcover using PATCHKEY and 2006 Ground Cover Index $(\mathrm{GCI})$ values $($ s.e. $=10.0)$.

The association between RCA sites assessed as D-condition and the remote sensing candidate D-condition mapping was tested in the Burdekin. For each RCA D-condition site a polygon was manually drawn onto the candidate D-condition mapping layer based on GPS coordinates and the side of the road nominated (i.e. a $3 \times 3$ Landsat TM pixel block or $5625 \mathrm{~m}^{2}$ allowing for subpixel registration error in the Landsat sequence).
Taking into consideration factors of vehicle speed and variable angle of observations in relation to the target (at $100 \mathrm{~km} \mathrm{~h}^{-1}$ it takes $3.6 \mathrm{~s}$ to travel $100 \mathrm{~m}$ ), a successful match was deemed to be any remotely sensed candidate D-condition class that was within $100 \mathrm{~m}$ of the polygon along track. Of the 253 RCA sites assessed as D-condition in the Burdekin, 41 sites were excluded from the assessment due to: land uses other than grazing (23); an abundance of weeds identified at the RCA site (10); or sites within areas mapped as having a woody FPC $>20 \%$ (8). For the remaining 212 RCA D-condition sites, $83 \%$ (177 sites) had a successful match between the remote and ground observation with $95 \%$ confidence interval of $76-86 \%$ for the true proportion (Table 6). There was no significant association $(P>0.05)$ between individual RCA attributes (i.e. groundcover, erosion, mid-story and tree crown cover) and the remote sensing classes. However, actual $P$-values for the erosion and mid-story variables were 0.080 and 0.076 , respectively, indicating a relationship at $P<0.10$ but not $P<0.05$.

The extent to which RCA surveys were 'representative' of the Burdekin region was also considered. The percentage of roads travelled in the Burdekin region was calculated by dividing the RCA track log (over the period 2004 to 2007) by the Geosciences Australia 1:500000 scale digital road coverage. Unsealed private property roads were generally not available for travel and likewise not shown at the scale of 1:500000 mapping. The percentage of roads travelled in the six primary catchments ranged from 38 to $76 \%$, and in four of the six catchments more than $50 \%$ of available roads were travelled.

\section{Discussion}

\section{Applying Landsat GCl in rangeland management}

The increase in Landsat GCI values between 2004 and 2006 in the Fox Creek subcatchment illustrates the capacity of remote sensing data to quantify vegetation change. In this case, we cannot be certain, without further investigation, whether this change was due to a sequence of rainfall events in combination with other seasonal factors or, perhaps, a result of management decisions to reduce cattle numbers following a 'poor' 2004 season. Pickup et al. (1994) and Wallace et al. (1994) demonstrated that at regional scales Landsat cover indices were largely climate driven. Yet, patterns at the paddock or property scale compared with the subcatchment average are of further significance. At the finer scales of paddock and property, the statistical summaries of remote sensing indices trend, variance and mean (e.g. Karfs and Trueman 2005; Wallace et al. 2006); histogram analysis (e.g. Wallace and Thomas 1999; Milne and Scarth 2008); and the directional change matrix (Bastin and the ACRIS Management Committee 2008) have value for filtering seasonal effects, and revealing differences that are likely to be more grazing management than climate driven.

We choose not to use property scale examples for this paper. However, we have experience in using the graphic evidence from Landsat GCI data for communicating changes in groundcover to landholders - providing feedback which land managers rarely receive, and generally appreciate (e.g. Beutel et al. 2005). When these time-series remote sensing data are supported by ground-based land condition assessments at the paddock or property scale (e.g. Aisthorpe and Paton 2004), they provide 


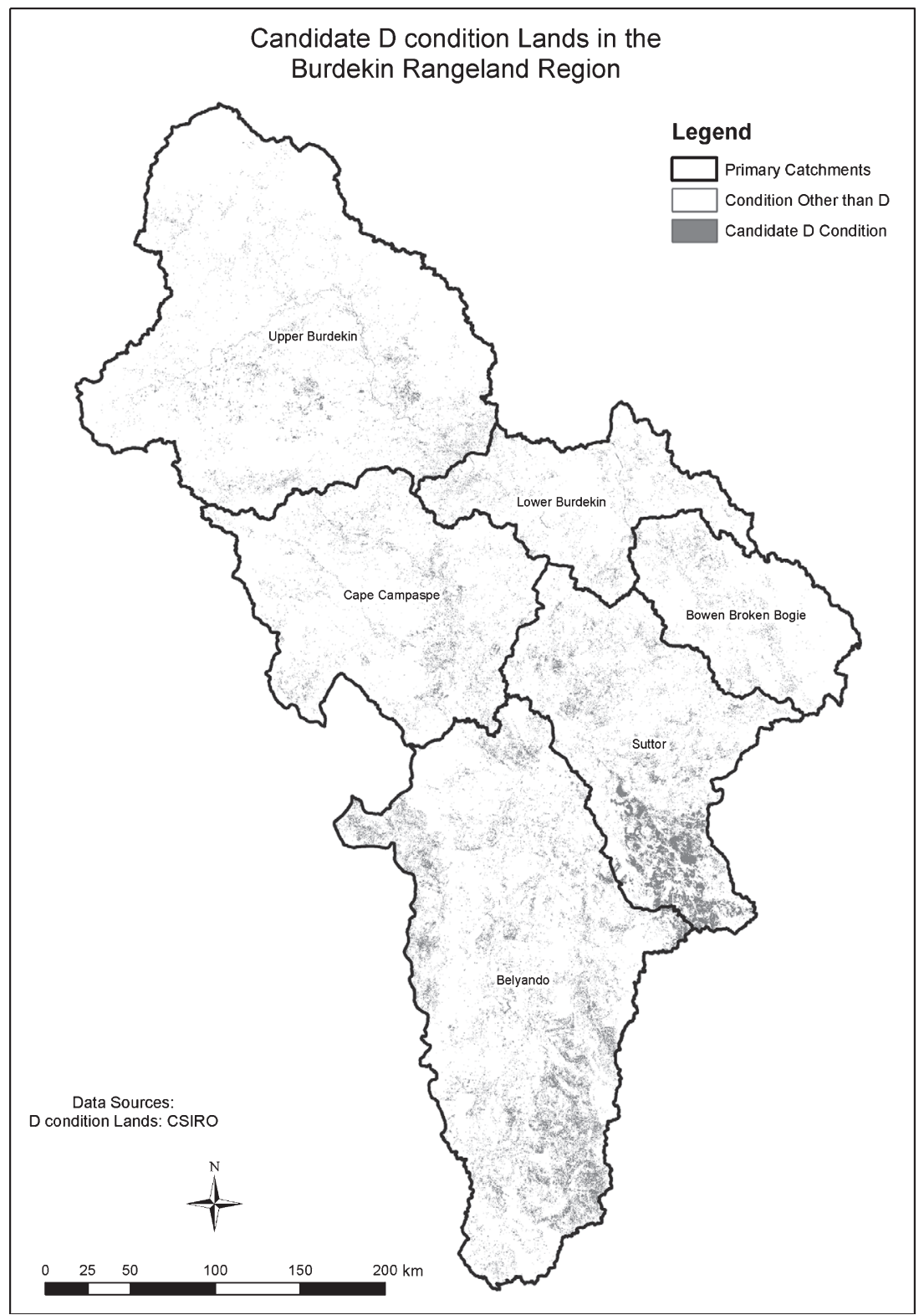

Fig. 7. Candidate D-condition landscapes in grazing lands of the Burdekin rangelands. Primary catchments of the Burdekin rangelands are indicated.

Table 4. Area and percentiles of remote sensing candidate D-condition classes for the Burdekin rangelands

\begin{tabular}{lcc}
\hline Class & $\begin{array}{c}\text { Estimated } \\
\text { area }\left(\mathrm{km}^{2}\right)\end{array}$ & $\begin{array}{c}\text { \% of Burdekin rangeland } \\
\text { grazing land use assessed } \\
\left(82421 \mathrm{~km}^{2}\right)\end{array}$ \\
\hline Acute single-date & 923 & 1.12 \\
Persistent multi-date & 1790 & 2.17 \\
Marginal multi-date & 3800 & 4.61 \\
Total & 6513 & 7.90 \\
\hline
\end{tabular}

landholders with the means to gather information over large areas and evaluate past management decisions. Among the landholders we spoke with, the ability to demonstrate a duty of care using the land condition monitoring products was seen as good practice, but it also made good business sense. Quantifying the areas of a property where management intervention might improve land condition, which would allow a quicker regeneration of pastures, may also mean a quicker turnover of cattle in the future. Comparing their properties with their peers - which also had similar climate/rainfall - was an important informal benchmarking and learning exercise for considering decisions that improve the business yet take into account the sustainability of the natural resource.

Users should appreciate that, when interpreting remote sensing groundcover monitoring data, Landsat GCI estimates, as with other cover indices, are not absolute for a given year (i.e. there is not a 1:1 relationship with actual groundcover). 


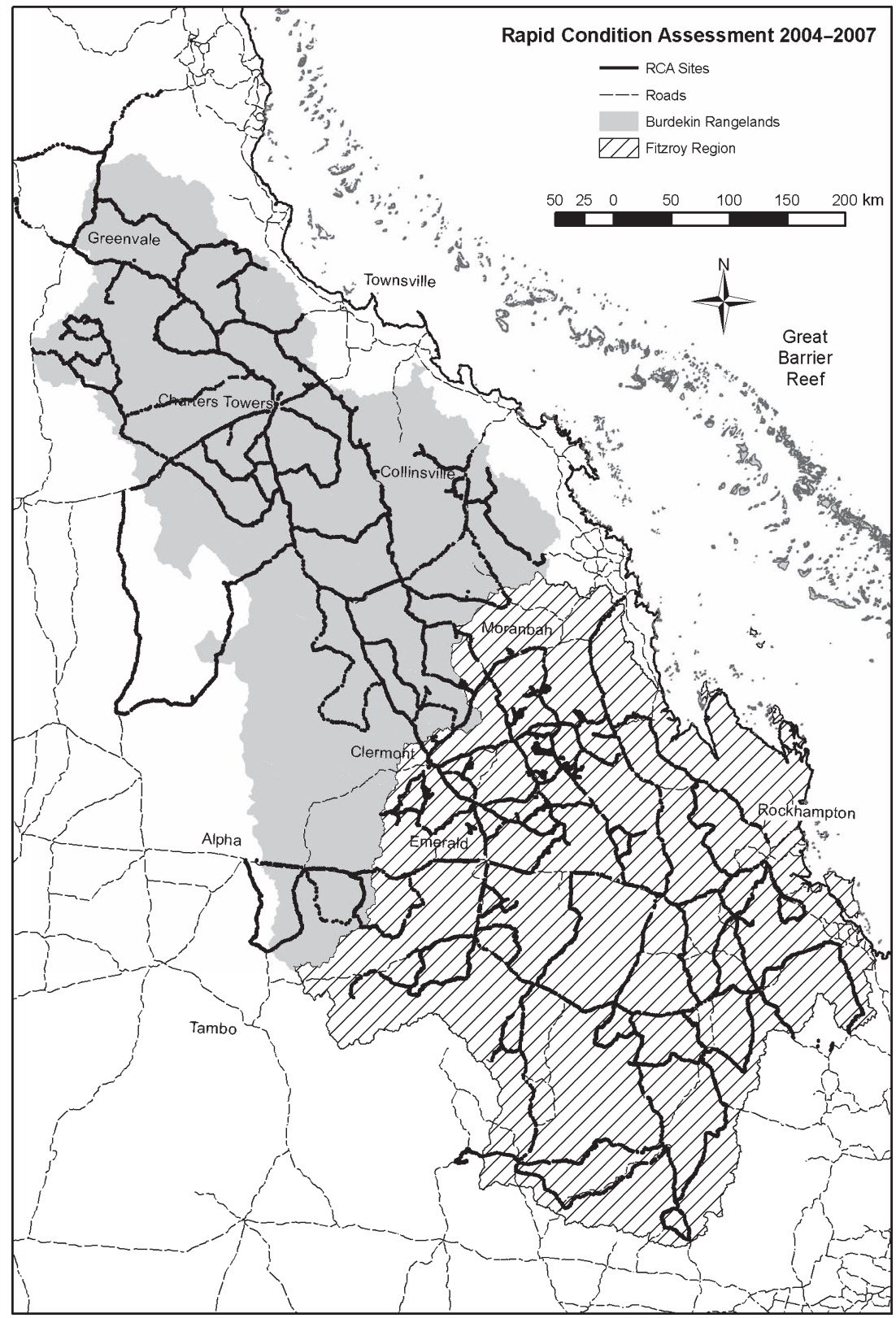

Fig. 8. Locations of Rapid Condition Assessment (RCA) sites in the Burdekin and Fitzroy regions. The overall number of sites assessed during the period 2004-07 was 10268 . Individual sites appear as a traverse at the scale of the figure.

Table 5. Summary of the number of Rapid Condition Assessment (RCA) sites collected during 2004-07 Cond. sites, Condition sites; Observ. sites, Observational sites

\begin{tabular}{|c|c|c|c|c|c|c|c|c|c|}
\hline \multirow[t]{2}{*}{ Year } & \multicolumn{3}{|c|}{ Burdekin } & \multicolumn{3}{|c|}{ Fitzroy } & \multicolumn{3}{|c|}{ Burdekin and Fitzroy combined } \\
\hline & $\begin{array}{c}\text { Cond. } \\
\text { sites }\end{array}$ & $\begin{array}{c}\text { Observ. } \\
\text { sites }\end{array}$ & $\begin{array}{c}\text { Total } \\
\text { Burdekin }\end{array}$ & $\begin{array}{l}\text { Cond. } \\
\text { sites }\end{array}$ & $\begin{array}{c}\text { Observ. } \\
\text { sites }\end{array}$ & $\begin{array}{l}\text { Total } \\
\text { Fitzroy }\end{array}$ & $\begin{array}{c}\text { Cond. } \\
\text { sites }\end{array}$ & $\begin{array}{c}\text { Observ. } \\
\text { sites }\end{array}$ & $\begin{array}{c}\text { Total } \\
\text { combined }\end{array}$ \\
\hline 2004 & 353 & 75 & 428 & - & - & - & 353 & 75 & 428 \\
\hline 2005 & 1168 & 298 & 1466 & 505 & 271 & 776 & 1673 & 569 & 2242 \\
\hline 2006 & 1321 & 26 & 1347 & 1026 & 222 & 1248 & 2347 & 248 & 2595 \\
\hline 2007 & 1177 & 245 & 1422 & 2759 & 822 & 3581 & 3936 & 1067 & 5004 \\
\hline Total & 4019 & 644 & 4663 & 4290 & 1315 & 5605 & 8309 & 1959 & 10268 \\
\hline
\end{tabular}


ABCD RCA Ratings, Burdekin 2004-2007 $n=4019$

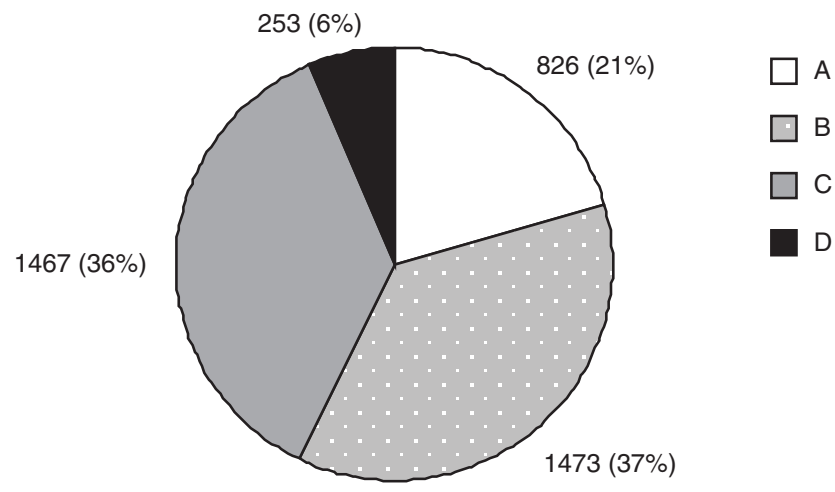

ABCD RCA Ratings, Fitzroy 2005-2007 $n=4290$

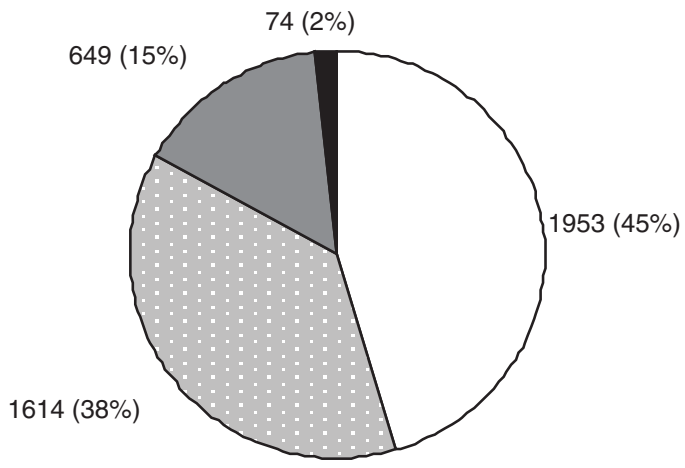

Fig. 9. Proportions of Rapid Condition Assessment (RCA) sites in ABCD condition for the Burdekin (top) and the Fitzroy (bottom). Note: data is for condition sites only.

Table 6. Proportions of Rapid Condition Assessment (RCA) D-condition sites matching remote sensing candidate D-condition ( $95 \%$ confidence interval of $76-86 \%$ for the true proportion)

D-Condition RCA site association to remote sensing candidate D-condition proportion of RCA sites

\begin{tabular}{lr}
\hline No Match & 35 \\
Match & 177 \\
Total & 212 \\
Percentage matching & $83 \%$ \\
\hline
\end{tabular}

The error inherent to groundcover estimates is derived from an inadequacy of sample numbers and distribution with which to calibrate the imagery precisely across the extensive areas of rangeland using conventional ground-based measurements (Jordaan et al. 1999; Booth et al. 2006; Johnson et al. 2008). Tracking groundcover change through time, i.e. comparing index values of the same $25 \mathrm{~m}$ pixels with themselves, is, therefore, a more consistent use of Landsat data than estimating absolute cover (Pickup et al. 1994; Wallace and Campbell 1998; Washington-Allen et al. 2006). Furthermore, cover index values alone may be unable to provide the precision required in some applications for identifying ecological processes operating at scales below the $900 \mathrm{~m}^{2}$ pixel size of the Landsat TM imagery (Ludwig et al. 2007b).

\section{Integrated land condition monitoring}

RCA condition sites aggregated to the regional scale indicated differences between the Burdekin and Fitzroy regions. For example, the proportion of sites assessed as 'A' condition in the Fitzroy was more than double that in the Burdekin. As site assessments were based on the capacity of the land for producing useful forage, areas sown with the introduced pasture species buffel grass (Cenchrus ciliaris), a prevalent feature in the Fitzroy (Thornton et al. 2007), were generally given an 'A' condition rating. In the Burdekin, the introduced species Indian couch (Bothriochloa pertusa), has colonised extensive parts of the catchment displacing more desirable native species (McKeon et al. 2004). Although Indian couch is a palatable perennial grass, it is generally not preferred for its production value (Wheaton 1994), and accordingly was given condition ratings of ' $\mathrm{B}$ ' and ' $\mathrm{C}$ '. Thus, in our land condition monitoring assessment the value of pasture plant species has contributed to regional differences observed in RCA rankings. In addition, the number of observation sites, i.e. non-land condition features encountered along traverse, in the Fitzroy was more than twice that of the Burdekin. This reflects general land use differences between the two regions, where in the Fitzroy cropping areas used for grain production is significantly greater. Finally, the proportion of RCA sites identified as very poor condition or D-condition was larger in the Burdekin ( $6 \%$ of sites) compared with the Fitzroy ( $2 \%$ of sites).

RCA ground observations and remote sensing results both showed a generally dispersed occurrence of candidate D-condition areas at a primary catchment scale in the Burdekin. Although confidence in these results were supported by PATCHKEY measures and a strong match between corresponding RCA and candidate D-condition data, there are several issues for mapping candidate D-conditions at the regional scale using remote sensing. First, areas of shared grazing/ agriculture may exist and not be masked using the latest QLUMP update (i.e. 2004). This would falsely weight the remote sensing mapping in that region by incorrectly assigning ploughed and fallow ground to candidate D-condition. Second, the marginal cover class was likely to include a significant proportion of ' $\mathrm{C}$ ' (poor) condition land that behaves similarly to D-condition landscapes, albeit with relatively more $3 \mathrm{P}$ grasses. We suggest that the marginal class is least accurate for candidate D-condition. Third, areas dominated by weed species often have groundcover that is stable, and have reflectance values greater than the GCI thresholds used for this study, leading to some D-condition areas not detected. Finally, the acute single-date candidate D-condition class mapped using SPOT 5 PAN imagery includes areas not related to grazing management, falsely adding a small proportion to the candidate D-condition total. These areas were associated with infrastructure, small gravel quarries, areas associated with water storage, and some dry river beds.

McKeon et al. (2004) provide a compelling account of historical pasture degradation in the Burdekin of which several key points are summarised below. A sequence of drought years 
in the mid-1980s combined with industry practices of retaining very high stock numbers, a change in preference to more drought tolerant cattle breeds, and the introduction of feed supplements to boost productivity and reduce deaths, seemed to be the culmination of circumstances leading to widespread degradation in the Burdekin. Degradation processes had been well under way by the time another extreme drought struck in the early 1990s, although a reduction in overall stock numbers may have reduced its impact. From Pressland and Turner (1983), a report by the Burdekin Project Committee (BPC 1976), estimated the area affected by soil erosion in the Upper Burdekin Catchment alone was $12.4 \%$ or $7000 \mathrm{~km}^{2}$. In the 1990s, De Corte et al. (1994) reported that in six of eight land types surveyed in the Dalrymple Shire region of the Burdekin, greater than $30 \%$ of sites exhibited sheet and scald erosion types. Tothill and Gillies (1992) estimated that $20 \%$ $\left(\sim 6700 \mathrm{~km}^{2}\right)$ of the northern black spear grass community in the Dalrymple Shire was in a degraded state that could not be regenerated or stabilised. The denudation of the soil surface through overgrazing seems to have coincided with the loss of native perennial tussock grasses; the spread of exotic grass species Indian couch; and the substantial contribution to sediment loads in the Burdekin River carried into the GBR. Ironically, grazing systems in Burdekin had been under a regime of apparently sustainable use for the 100 years before changes in grazing practices in the 1960 s and ' 70 s.

Here, we were unable to conclude whether the historically degraded landscapes in the Burdekin region have since stabilised or improved (e.g. with a change in pasture species to Indian couch). The only analogous baseline to compare our results was Landsat TM data from an earlier period (i.e. 1987-96). A comparison with the earlier TM data was beyond the scope of the project, and, in any case, this assessment would have had to be done without any source of historical ground data for much of the Burdekin. For these reasons, we recommend conducting a more rigorous ground-based validation procedure (e.g. Stehman 2001) than achieved in this project. Such a benchmark of land condition from a 'bottom up' perspective (i.e. the amount of area under D-condition) would allow quantifiable assessment of overall land condition change at the end of the next 10 years. To gauge that trend against the change that is attributable to changes in management practices and or targeted NRM activities. Follow-up RCA monitoring that specifically targets the areas of tree cover masked in the remote sensing analysis is recommended. In addition, we suggest further testing of an experimental landscape vulnerability index (as discussed by Abbott et al. 2008) that combined multiple spatial layers, including the candidate D-condition layer, to identify potential landscapes susceptible to D-condition in the Burdekin whether densely wooded or not.

The remote sensing and RCA spatial layers as they are, however, provide NRM regional bodies BDT and FBA with an increased ability to integrate (and weigh against) data from other sources to guide decision-making. Some examples include the following. Stone et al. (2008) have indicated the stability or some loss in landscape function in the Burdekin region from 1991 to 2005 , based on regional AussieGrass time-series pasture utilisation simulations (Carter et al. 2000), and repeated roadside estimates of biomass land condition attributes (Hassett et al.
2000). Bastin et al. (2008) have demonstrated, that Indian Couch pastures are at risk in the Burdekin of become excessively leaky (decreasing landscape function) and unproductive in times of drought where higher levels of groundcover are not maintained. With respect to water quality, the spatially variable remote sensing groundcover information has input value for systems analysis in Reef catchments using the SedNet model (Prosser et al. 2001) to identify soil loss potential and management priorities; and for direct comparisons with in-stream water quality measurements (e.g. Bainbridge et al. 2007). Finally, datasets that track changes in several biophysical, social and economic indicators are now available - for the first time - at National and regional scales for Australian rangelands, through the Australian Collaborative Rangeland Information System (ACRIS - Bastin and the ACRIS Management Committee 2008).

\section{A new era}

NRM regional bodies face challenges in leading the community towards achieving a balance between natural, social and economic systems for the benefit of future generations. A spectrum of drivers (e.g. physical, social, policy) that impact rangeland ecosystems needs to be considered (Brown and Havstad 2004). Within this intricate web of knowledge, spatial information on land condition and trend is a critical component. This paper has described new datasets delivered to NRM regional bodies BDT and FBA for better understanding land condition in what are enormous tracts of country. These datasets have already provided value in planning decisions. For example, the NRM regional bodies have integrated land condition monitoring information with other thematic data in their own GIS databases, for helping identify priority investment areas (e.g. improving groundcover management practices for reducing hillslope erosion risk as part of the Australian Government's NRM initiative 'Caring for our Country' - www.nrm.gov.au/, accessed 15 November 2008). Similarly, the multi-temporal data provide the NRM regional bodies with a baseline for reviewing the effect of previous incentives and grants, or any other project intervention, in the past 5-10 years of NRM investment. Thus, as a direct result of this project's activity, improved capacity for making strategic NRM decisions has been transferred to the local level. This outcome has occurred only through the collaborative effort of multiple agencies that, like the regional bodies, strive towards the goal of balanced production systems and sustainable NRM.

In this regard, we observe a 'new era' emerging for the application and use of land condition monitoring information in respect to:

(1) an increased openness to share information under a wholeof-government approach (MAC 2004);

(2) wider access to spatial data by 'non-expert' associates and their clients, e.g. public funded research made available to the public (Seelan et al. 2007; QSIC 2008);

(3) decreasing costs of critical time-series Landsat satellite data (US Geological Survey website http://landsat.usgs.gov/, Accessed 15 November 2008);

(4) increased technology and capacity of computing hardware and software to view, manipulate and interrogate large datasets (e.g. ANZLIC 2008); 
(5) improved contact and technology transfer with rural clients through increased use of information and communication technology (ICT), emphasised by the trend towards eGovernment (DFA 2006); and

(6) the active involvement and investment of industry and community, along with all levels of government that places greater emphasis on education, awareness and community engagement (global change to 'client centric' view for government, e.g. OPSC 2008).

Ultimately, NRM decisions for improving the condition in grazing lands of the Burdekin and Fitzroy fall upon individual landholders. In some cases, these landholders may not be aware of how their management can impact the broader catchment and eventually the GBR. Therefore, to realise the benefits of land condition monitoring information and influence changes in management, the information needs to be produced in a timely manner and made available in a format that is intuitive, reliable and convenient to access. One landholder we spoke to put it simply, "the value of remote sensing data is in creating an awareness of any issues on our land; we want to know about it so we can take ownership of the problem and work on ways to fix it' (CQ Beef Meeting - November 2007). In an era where external drivers are increasing the need to improve the efficiency of production (Ash and Stafford Smith 2003), objective land condition monitoring information that helps in optimising the use of pastures in an environmentally sustainable manner could become commercially advantageous. A significant challenge then will be in assisting landholders recognise the value of this information, in making proactive decisions that are suited to prevailing and predicted climatic conditions, and that improve overall land management. Training and education will be essential through partnerships that promote two-way communication. These partnerships should include professionals with knowledge of rangeland ecosystems and interpreting land condition monitoring results (Brown and Havstad 2004), and landholders with knowledge of the land and its management (e.g. Landsberg et al. 1998) who are empowered by the targeted activities of the NRM community. Together, this alliance can build a balanced approach for reducing the wider threat of human activity in grazing lands upstream of a natural wonder that is the GBR.

\section{Concluding remarks}

This paper has presented methods and examples used to produce new land condition monitoring information in the Burdekin and Fitzroy regions. This outcome was a result of collaboration and science integration between multiple agencies over a period of 2 years. The innovation was putting the data together and delivering spatial datasets to NRM Regional Body partners, for their use in building organisational capacity to better understand land condition at multiple scales, and for providing support in making strategic investments.

Across the vast extent of these regions, the issue of inadequate sample size and distribution of site-based sampling was addressed through the use of remote sensing data. Annual Landsat TM satellite data spanning the past 20+ years has allowed identification of when and where changes in groundcover had occurred at multiple spatial and temporal scales.
Through integrating Landsat time-series with high resolution SPOT 5 PAN imagery and numerous subjective ground-based 'windscreen' assessment sites, we have provided a unique spatial dataset indicative of the locations of very poor condition in the Burdekin region (estimated between 3.3 and $7.9 \%$ in nearly three quarters of the Burdekin rangelands under a grazing land use). This land condition class 'end member' was characterised by recurrent bare ground and low groundcover, and precludes very poor condition areas infested by weeds or thickets of woody vegetation. This dataset provides an innovative benchmark for which to measure the successes or failure of present NRM activity into the future. The remote identification of all land conditions (from good to poor) at regional scales, however, it remains a challenge, particularly in respect to condition classifications and the value of pasture species that are of recognised importance to the grazing industry. Therefore, remote sensing and ground validation will remain interdependent components of any future land condition monitoring activity in rangelands.

We believe that a better understanding of the broad picture, as presented by these new spatial datasets, will greatly improve the quantification of land condition in the Burdekin and Fitzroy regions. Likewise, users of spatial outputs now have an ability to integrate these data with other sources of information in their decision-making processes. For NRM Regional Bodies that have a shared responsibility for improving water quality in GBR catchments, the availability of these data signal an emerging capability not seen before in the use and application of land condition monitoring information.

\section{Acknowledgements}

This work was conducted through financial support received from NRM regional bodies the Burdekin Dry Tropics and the Fitzroy Basin Association, in collaboration with Queensland Government Departments Primary Industries and Fisheries, and Natural Resources and Water, and the Commonwealth Scientific and Industrial Research Organisation. The authors acknowledge the contribution of project members Terry Beutel, Tim Danaher, Chris Holloway, Jeff Milne, Justin Perry and Kim Pritchard, and statistical analysis by Angela Reid as well as the support from other staff members in our respective agencies. The paper was considerably improved by the comments from John Ludwig and an anonymous reviewer. Lastly, thanks to the many Burdekin and Fitzroy region landholders who we visited, their hospitality and views on local land condition were greatly appreciated.

\section{References}

Abbott, B., Perry, J., and Wallace, J. (2008). Prioritisation of D-condition land for rehabilitation. Report to BDT as part of Land Condition Monitoring Project - Task 4. CSIRO Sustainable Ecosystem, Townsville.

Abbott, B. N., and Corfield, J. P. (2006). Putting PATCHKEY into practice investigating landscape scale patchiness. In: 'Renmark 2006, the Cutting Edge. Australian Rangeland Society 14th Biennial Conference'. Renmark, SA, 3-7 September 2006. (Ed. P. Erkelenz.) pp. 21-24. (Australian Rangeland Society: Adelaide.)

Aisthorpe, J., and Paton, C. (2004). 'Stocktake. Balancing Supply and Demand.' (Department of Primary Industries and Fisheries: Brisbane.)

ANZLIC (The Spatial Information Council of Australia and New Zealand) (2008). The value of spatial information. A report prepared for the CRC for Spatial Information and ANZLIC, by ACIL Tasman Pty. Ltd., Spatial Information Systems Limited, March 2008. Available at: www. crcsi.com.au/pages/publications.aspx (Accessed 7 August 2008). 
Ash, A., Corfield, J., and Ksiksi, T. (2002). 'The Ecograze Project Developing Guidelines to Better Manage Grazing Country.' (CSIRO Sustainable Ecosystems: Townsville, Qld.)

Ash, A., and Stafford Smith, M. (2003). Pastoralism in tropical rangelands: seizing the opportunity to change. The Rangeland Journal 25, 113-127. doi: $10.1071 /$ RJ03010

Australian Bureau of Statistics (2008). Regional population growth, Australia, 2006-07 (released 31/03/2008). Available at: www.abs.gov.au/ AUSSTATS/abs@.nsf/Lookup/3218.0Main\%20Features72006-07? opendocument $\&$ tabname $=$ Summary $\&$ prodno $=3218.0 \&$ issue $=2006-$ 07\&num=\&view (Accessed 2 March 2009).

Bainbridge, Z. T., Lewis, S. E., and Brodie, J. E. (2007). Sediment and nutrient exports for the Burdekin River catchment, north Queensland: a comparison of monitoring and modelling data. In: 'MODSIM 2007 International Congress on Modelling and Simulation'. (Eds L. Oxley and D. Kulasiri.) pp. 874-880. (Modelling and Simulation Society of Australia and New Zealand.)

Bastin, G., Abbott, B., Karfs, B., Holloway, C., Liedloff, A., and Chewings, V. (2008). Landscape leakiness in the grazed rangelands of the Burdekin. In: 'Proceedings 15th Biennial Australian Rangeland Society Conference'. Charters Towers, Queensland, 28 September-2 October 2008. pp. 48-51. (Australian Rangeland Society: Townsville, Qld.)

Bastin, G., and the ACRIS Management Committee (2008). Rangelands 2008 - Taking the Pulse. Published on behalf of the Australian Collaborative Rangeland Information System (ACRIS) Management Committee by the National Land and Water Resources Audit, Canberra.

Bastin, G. N., and Ludwig, J. L. (2006). Problems and prospects for mapping vegetation condition in Australia's arid rangelands. Ecological Management \& Restoration 7, S71-S74. doi: 10.1111/j.14428903.2006.293_4.x

Bastin, G. N., Pickup, G., Stanes, J., and Stanes, A. (1996). Estimating landscape resilience from satellite data and its application to pastoral land management. The Rangeland Journal 18, 118-135. doi: 10.1071/ RJ9960118

Bastin, G. N., Stafford Smith, D. M., Watson, I. W., and Fisher, A. (2009). The Australian Collaborative Rangelands Information System: preparing for a climate of change. The Rangeland Journal 31, 111-125.

Beutel, T. S., Karfs, R. A., Bull, A. L., Peel, L., and Wallace, J. F. (2005). VegMachine - putting pastoralists in the picture. Agricultural Science 17, 18-20.

Booth, D. T., Cox, S. E., Meikle, T. W., and Fitzgerald, C. (2006). The accuracy of ground-cover measurements. Rangeland Ecology and Management 59, 179-188. doi: 10.2111/05-069R1.1

Booth, D. T., and Tueller, P. T. (2003). Rangeland monitoring using remote sensing. Arid Land Research and Management 17, 455-478. doi: 10.1080/713936105

BPC (Burdekin Project Committee) (1976). 'Resources and potential of the Burdekin River Basin, Queensland. Land and Associated Features.' (Australian Government Publishing Service: Canberra.)

Brodie, J., McKergow, L. A., Prosser, I. P, Furnas, M., Hughes, A. O., and Hunter, H. (2004). Sources of Sediment and Nutrient Exports to the Great Barrier Reef World Heritage Area. Australian Centre for Tropical Freshwater Research, Report No. 03/11. Available at: www.actfr.jcu.edu. au/staff/jon2.htm (Accessed 5 August 2008).

Brown, J. R., and Havstad, K. M. (2004). Monitoring to detect change on rangelands: physical, social and economic/policy drivers. African Journal of Range \& Forage Science 21, 115-121.

Caccetta, P. A., Campbell, N. A., Evans, F. H., Furby, S. L., Kiiveri, H. T., and Wallace, J. F. (2000). Mapping and monitoring land use and condition change in the South-West of Western Australia using remote sensing and other data. In: 'Proceedings of the Europa 2000 Conference'. Barcelona, Spain. Available at: www.cmis.csiro.au/rsm/publications.htm (Accessed 25 August 2008).
Carter, J., Hall, W., Brook, K., McKeon, G., Day, K., and Paull, C. (2000). AUSSIE GRASS: Australian grassland and rangelands assessment by spatial simulation. In: 'Applications of Seasonal Climate Forecasting in Agricultural and Natural Ecosystems: the Australian Experience'. (Eds N. G. Hammer and C. Mitchell.) pp. 329-349. (Kluwer Academic Publishers: The Netherlands.)

Chilcott, C. R., Paton, C. J., Quirk, M. F., and McCallum, B. S. (2003). 'Grazing Land Management Education Package Workshop Notes Burnett.' (Meat and Livestock Australia Limited: Sydney.)

Corfield, J. P., Abbott, B. N., Hawdon, A., and Berthelsen, S. (2006). PATCHKEY: a patch classification framework for the upper Burdekin and beyond. In: 'Renmark 2006, the Cutting Edge. Australian Rangeland Society 14th Biennial Conference'. Renmark, SA, 3-7 September 2006. (Ed. P. Erkelenz.) pp. 114-118. (Australian Rangeland Society: Adelaide.)

Danaher, T., Armston, J., and Collet, L. (2004). A regression model approach for mapping woody foliage projective cover using Landsat imagery in Queensland, Australia. In: 'IGARSS 2004. Proceedings of the 24th Annual International Geoscience and Remote Sensing Symposium'. September 2004. (Institute of Electrical and Electronics Engineers: Anchorage, Alaska.)

Danaher, T. J. (2002). An empirical BRDF correction for Landsat TM and ETM+ imagery. In: 'Proceedings of the 11th Australasian Remote Sensing and Photogrammetry Conference'. September 2002, Brisbane, Qld. pp. 1102-1109. (Photogrammetry Association of Australasia: Brisbane, Qld.)

De Corte, M. W. M., Barry, E. V., Bright, M. J., Cannon, M. G., and Scanlan, J. C. (1994). Land degradation in the Dalrymple Shire, a preliminary assessment, methods and results. Project Report Q093023, Queensland Department of Primary Industries, Brisbane.

De Vries, C., Danaher, T., and Scarth, P. (2004). Calibration of multiple Landsat sensors based on pseudo-invariant target sites in Western Queensland, Australia. In: 'IGARSS 2004. Proceedings of the 24th Annual International Geoscience and Remote Sensing Symposium'. September 2004. pp. 3729-3732. (Institute of Electrical and Electronics Engineers: Anchorage, Alaska.)

DFA (Department of Finance and Administration) (2006). 2006 e-Government Strategy; Responsive Government - A New Service Agenda. Australian Government Information Management Office, Commonwealth of Australia. Available at: www.finance.gov.au/ publications/2006-e-government-strategy/index.html (Accessed 19 September 2008).

DPI\&F (2008). Prospects for Queensland's primary industries 2007-08. Department of Primary Industries and Fisheries, Queensland. June 2008. Available at: www.dpi.qld.gov.au/documents/BusinessAndTrade_ IndustryTrends/ProspectsUpdate-Jun08.pdf (Accessed 25 August 2008).

Dube, S., Kalua, F., and Mkunggurutse, M. (1999). The importance of ground-cover in reducing erosion and run-off in a semi-arid rangeland. In: 'People and Rangelands: Building the Future. Proceedings VI International Rangeland Congress'. Townsville. (Eds D. Eldridge and D. Freudenberger.) pp. 706-707. (VI International Rangeland Congress Inc.: Townsville, Qld.)

Fentie, B., Duncan, I., Sherman, B. S., Read, A., Chen, Y., Brodie, J., and Cogle, A. L. (2006). Sediment and nutrient modelling in the Burdekin NRM region. Vol. 3. In: 'The Use of SedNet and ANNEX Models to Guide GBR Catchment Sediment and Nutrient Target Setting'. (Eds A. L. Cogle, C. Carroll and B.S. Sherman.) (Department of Natural Resource, Mines and Water.)

Friedel, M. H., Laycock, W. A., and Bastin, G. N. (2000). Assessing rangeland condition and trend. In: 'Field and laboratory methods for grassland and animal production research'. (Eds L. T. Mannetje and R. M. Jones.) pp. 227-262. (Commonwealth Agricultural Bureaux Publication: Wallingford, UK.) 
Fugawi (2007). Fugawi Global Navigator. Northport Systems Inc., Toronto, Canada. Available at: www.fugawi.com/web/index-in.htm (Accessed 20 May 2008).

Garmin (2005). Garmin GPSMap 60 Series. GME a Division of Standard Communications Pty. Ltd. Available at: www.gme.net.au/garmin/PDFs/ gpsmap60c_broch.pdf (Accessed 20 May 2008).

Graetz, R. D., and Gentle, M. R. (1982). The relationships between reflectance in Landsat wavebands and the composition of an Australian semi-arid shrub rangeland. Photogrammetric Engineering and Remote Sensing 48, 1721-1730.

Graetz, R. D., Pech, R. P., and Davis, A. W. (1988). The assessment and monitoring of sparsely vegetated rangelands using calibrated Landsat data. International Journal of Remote Sensing 9, 1201-1222. doi: $10.1080 / 01431168808954929$

Gunn, R. H., Beattie, J. A., Reid, R. E., and van de Graaff, R. H. M. (Eds) (1988). 'Australian Soil and Land Survey Handbook: Guidelines for Conducting Surveys.' (Inkata Press: Melbourne.)

Hassett, R. C., Wood, J. L., Carter, J. O., and Danaher, T. J. (2000). A field method for Statewide ground-truthing of a spatial model. Australian Journal of Experimental Agriculture 40, 1069-1079. doi: 10.1071/ EA00010

Jafari, R., Lewis, M. M., and Ostendorf, B. (2007). Evaluation of vegetation indices for assessing vegetation cover in southern arid lands in South Australia. The Rangeland Journal 29, 39-49. doi: 10.1071/ RJ06033

Jeffrey, S. J., Carter, J. O., Moodie, K. M., and Beswick, A. R. (2001). Using spatial interpolation to construct a comprehensive archive of Australian climate data. Environmental Modelling \& Software 16, 309-330. doi: 10.1016/S1364-8152(01)00008-1

Johnson, M. D., Harris, N. R., Louhaichi, M., Clark, P., and Johnson, D. E. (2008). A protocol for monitoring vegetation, bare ground and litter in scaled globally-positioned, ground-level digital imagery. In: '2008 Annual Conference Proceedings of the ASPRS'. 28 April-2 May 2008, Portland, OR. (American Society for Photogrammetry and Remote Sensing.)

Jordaan, F. P., Watson, I. W., and Booysen, J. (1999). Monitoring and resource accounting at the paddock and property scale. In: 'People and Rangelands: Building the Future. Proceedings VI International Rangeland Congress'. Townsville. (Eds D. Eldridge and D. Freudenberger.) pp. 721-726. (VI International Rangeland Congress, Inc.: Townsville, Qld.)

Karfs, R., Applegate, R., Fisher, R., Lynch, D., Mullin, D., Novelly, P., Peel, L., Richardson, K., Thomas, P., and Wallace, J. (2000). Regional land condition and trend assessment in tropical savannas: the Audit Rangeland Implementation Project Final report. National Land and Water Resources Audit, Canberra. Available at: www.anra.gov.au/topics/rangelands/project/index.html (Accessed 20 July 2008).

Karfs, R. A. (2002). Rangeland monitoring in tropical savanna grasslands Northern Territory, Australia: relationships between temporal satellite data and ground data. Masters Thesis, Research School of Tropical Environment Studies and Geography, James Cook University, North Queensland, Australia.

Karfs, R. A., and Saunders, N. J. (2004). Rangeland Assessment of the Barkly Pastoral District 2004. Report to the NT Pastoral Land Board, October 2004, Land Monitoring Branch. Northern Territory Department of Infrastructure, Planning and Environment, Darwin.

Karfs, R. A., and Trueman, M. (2005). Tracking Changes in the VRD Pastoral District, Northern Territory, Australia - 2005. Report to the Australian Collaborative Rangeland Information System (ACRIS) Management Committee. NT Department of Natural Resources Environment and the Arts, Darwin. Available at: http://eriss.erin.gov. au/land/publications/acris/nt.html (Accessed 25 August 2008).
Landsberg, R. G., Ash, A. J., Shepherd, R. K., and McKeon, G. M. (1998). Learning from history to survive in the future: management evolution on Trafalgar station, north-east Queensland. The Rangeland Journal 20, 104-118. doi: 10.1071/RJ9980104

Lawes, R. A., and Wallace, J. F. (2008). Monitoring an invasive perennial at the landscape scale with remote sensing. Ecological Management \& Restoration 9, 53-59. doi: 10.1111/j.1442-8903.2008.00387.x

Ludwig, J. A., Bastin, G. N., Chewings, V. H., Eager, R. W., and Liedloff, A. C. (2007a). Leakiness: a new index for monitoring the health of arid and semiarid landscapes using remotely sensed vegetation cover and elevation data. Ecological Indicators 7, 442-454. doi: 10.1016/j.ecolind.2006.05.001

Ludwig, J. A., Bastin, G. N., Eager, R. W., Karfs, R., Ketner, P., and Pearce, G. (2000). Monitoring Australian rangeland sites using landscape function indicators and ground- and remote-based techniques. Environmental Monitoring and Assessment 64, 167-178. doi: 10.1023/ A: 1006475825546

Ludwig, J. A., Bastin, G. N., Wallace, J. F., and McVicar, J. R. (2007b). Assessing landscape health by scaling with remote sensing: when is it not enough? Landscape Ecology 22, 163-169. doi: 10.1007/s10980-0069038-6

MAC (Management Advisory Committee) (2004). 'Connecting Government, whole of Government responses to Australia's priority challenges.' (Good Practice Guides, Department of Communications, Information Technology and the Arts, Commonwealth of Australia: Canberra.)

MacLeod, N. D., Ash, A. J., and McIvor, J. G. (2004). An economic assessment of the impact of grazing land condition on livestock performance in tropic woodlands. The Rangeland Journal 26, 49-71. doi: 10.1071/RJ04004

McDonald, R. C., Isbell, R. F., Speight, J. G., Walker, J., and Hopkins, M. S. (1990). 'Australian Soil and Land Survey Field Handbook.' 2nd edn reprint. (Department of Primary Industries and Energy and CSIRO Australia.)

McIvor, J. G., Williams, J., and Gardener, C. J. (1995). Pasture management influences runoff and soil movement in the semi-arid tropics. Australian Journal of Experimental Agriculture 35, 55-65. doi: 10.1071/ EA9950055

McKeon, G. M., Hall, W. B., Crimp, S. J., Howden, S. M., Stone, R. C., and Jones, D. A. (1998). Climatic change in Queensland's grazing lands. I. Approaches and climatic trends. The Rangeland Journal 20, 151-176. doi: 10.1071/RJ9980151

McKeon, G. M., Hall, W. B., Henry, B. K., Stone, G. S., and Watson, I. W. (2004). 'Pasture Degradation and Recovery in Australia's Rangelands: Learning from History.' (Queensland Department of Natural Resources Mines and Energy.)

Milne, J., and Scarth, P. (2008). Land condition monitoring in the Burdekin Dry Tropics Region. Final Report to BDT as part of Land Condition Monitoring Project - Task 2. NRW, Brisbane.

Mundt, J. T., Strutker, D. R., and Glenn, N. F. (2006). Mapping sagebrush distribution using fusion of hyperspectral and Lidar classifications. Photogrammetric Engineering and Remote Sensing 72, 47-54.

Murphy, S. R., and Lodge, G. M. (2002). Ground cover in temperate native perennial grass pastures. I. A comparison of four estimation methods. The Rangeland Journal 24, 288-300. doi: 10.1071/RJ02016

NASA (National Aeronautical and Space Administration) (2004). Landsat 7 Science Data Users Handbook. Available at: http://landsathandbook.gsfc. nasa.gov/handbook.html (Accessed 16 July 2008).

NRMMC (Natural Resource Management Ministerial Council) (2002). National Natural Resource Management Capacity Building Framework, Australian Government Departments of the Environment and Heritage and Agriculture, Fisheries and Forestry. Available at: www.daff.gov.au/ natural-resources/about_natural_resource_management/capacitybuilding (Accessed 7 January 2009). 
O'Reagain, P. J., McKeon, G. M., Day, K. A., and Ash, A. (2003). Managing for temporal variability in extensive rangelands - a northern Australia perspective. In: 'Rangelands in the new millennium. 7th International Rangelands Congress'. 26 July-1 August 2003, Durban. (Eds N. Allsop et al.) pp. 799-809. (The Congress: Durban, South Africa.)

Okin, G. S., Roberts, D. A., Murry, B., and Okin, W. J. (2001). Practical limits on hyperspectral vegetation discrimination in arid and semiarid environments. Remote Sensing of Environment 77, 212-225. doi: 10.1016/S0034-4257(01)00207-3

OPSC (Office of the Public Service Commissioner) (2008). Sustaining the QPS workforce in a tight labour environment: key research findings. Occasional Paper 05/08, Office of the Public Service Commissioner, Queensland Government. Available at: www.opsc.qld.gov.au/resources/ publications_and_forms/notices.shtml (Accessed 15 August 2008).

OSTP (US Office of Science and Technology Policy) (2007). A plan for a U.S. National Land Imaging Program. Future of Land Imaging Interagency Working Group, US Office of Science and Technology Policy, Executive Office of the President of the United States. Available at: www.landimaging.gov/fli_iwg_report_print_ready_low_res.pdf (Accessed 17 March 2008).

Payne, A. L., Van Vreeswyk, A. M. E., Pringle, H. J. R., Leighton, K. A., and Hennig, P. (1998). An inventory and condition survey of the SandstoneYalgoo-Paynes Find area, Western Australia. Agriculture Western Australia Technical Bulletin No. 90.

Pech, R. P., Graetz, R. D., and Davis, A. W. (1986). Reflectance modelling and the derivation of vegetation indices for an Australian semi-arid shrubland. International Journal of Remote Sensing 7, 389-403. doi: $10.1080 / 01431168608954694$

Pickup, G., Chewings, V. H., and Nelson, D. J. (1993). Estimating changes in vegetation cover over time in arid rangelands using Landsat MSS data. Remote Sensing of Environment 43, 243-263. doi: 10.1016/ 0034-4257(93)90069-A

Pickup, G., Bastin, G. N., and Chewings, V. H. (1994). Remote sensing-based condition assessment for non-equilibrium rangelands under large-scale commercial grazing. Ecological Applications 4, 497-517. doi: 10.2307/ 1941952

Pickup, G., Bastin, G. N., and Chewings, V. H. (1998). Identifying trends in land degradation in non-equilibrium rangelands. Journal of Applied Ecology 35, 365-377. doi: 10.1046/j.1365-2664.1998.00319.x

Pickup, G., Bastin, G. N., and Chewings, V. H. (2000). Measuring rangeland vegetation with high resolution airborne videography in the blue-near infrared spectral region. International Journal of Remote Sensing 21, 339-351. doi: 10.1080/014311600210867

Pressland, A. J., and Turner, E. J. (1983). Interaction between grazing management and erosion in the upper Burdekin Catchment - a proposed work schedule. A Queensland Department of Primary Industries internal report.

Prosser, I., Rustomji, P., Young, B., Moron, C., and Hughes, A. (2001). Constructing river basin sediment budgets for the National Land and Water Resources Audit. CSIRO Land and Water, Technical Report 15/01. Available at: www.clw.csiro.au/technical2001/tr15-01.pdf (Accessed 6 March 2007).

QSIC (Queensland Spatial Information Council) (2008). Strategic Plan 2008-11. Available at: www.qsic.qld.gov.au/qsic/QSIC.nsf/0/A5A6D 6D43E2973264A257478000D36F7/\$FILE/QSIC\%20Strategic\%20 Plan\%202008-2011\%20PDF.pdf?openelement (Accessed 7 August 2008).

Richards, G., and Furby, S. L. (2002). Subhectare land cover monitoring: developing a national scale time-series program. In: 'Proceedings of 11 th Australasian Remote Sensing and Photogrammetry Conference'. 2-6 September 2002. Available at: www.cmis.csiro.au/rsm/publications.htm (Accessed 25 August 2008).
Roth, C. (2004). A framework relating soil surface condition to infiltration and sediment and nutrient mobilisation in grazed rangelands of northeastern Queensland. Earth Surface Processes and Landforms 29, 1093-1104. doi: 10.1002/esp.1104

Scarth, P., Byrne, M., Danaher, T., Henry, B., Hassett, R., Carter, J., and Timmers, P. (2006). State of the paddock: monitoring condition and trend in groundcover across Queensland. In: 'Earth observation from science to solutions. 13th Australasian Remote Sensing Conference'. November 2006. (The Remote Sensing and Photogrammetry Commission of the Spatial Sciences Institute: Canberra.)

Seelan, S. K., Baumgartner, D., Casady, G. M., Nangia, V., and Seielstad, G. A. (2007). Empowering farmers with remote sensing knowledge: a success story from the US Upper Midwest. Geocarto International 22, 141-157. doi: 10.1080/10106040701207134

Stehman, S. V. (2001). Statistical rigor and practical utility in thematic map accuracy assessment. Photogrammetric Engineering and Remote Sensing 67, 727-734.

Stone, G., Bruget, D., Carter, J., Hassett, G., McKeon, G., and Rayner, D. (2008). Pasture production and condition. State of Environment Queensland 2007. Queensland Environmental Protection Agency. Available at: www.epa.qld.gov.au/environmental_management/state_ of_the_environment/state_of_the_environment_queensland_2007 (Accessed 15 August 2008).

Taube, C. (2000). Estimating ground-cover in semi-arid rangelands using Landsat Thematic Mapper imagery. Research Thesis for Master of Science, Geographical Sciences and Planning Department, University of Queensland, Australia.

Thornton, C. M., Cowie, B. A., Freebairn, D. M., and Playford, C. L. (2007). The Brigalow Catchment Study: II. Clearing brigalow (Acacia harpophylla) for cropping or pasture increases runoff. Australian Journal of Soil Research 45, 496-511. doi: 10.1071/SR07064

Tongway, D. J., and Hindley, N. L. (2004). Landscape function analysis manual: Procedures for monitoring and assessing landscapes. CSIRO Sustainable Ecosystems, ver. 3.1, May 2004, (CD-ROM).

Tothill, J. C., and Gillies, C. (1992). The pasture lands of northern Australia: their condition, productivity and sustainability. Occasional Publication No. 5. Tropical Grassland Society of Australia, Queensland.

Wallace, J., Behn, G., and Furby, S. (2006). Vegetation condition assessment and monitoring from sequences of satellite imagery. Ecological Management \& Restoration 7, S31-S36. doi: 10.1111/j.1442-8903. 2006.00289.x

Wallace, J., and Thomas, P. (1999). Monitoring and summarizing rangeland changes using sequences of Landsat data. In: 'People and Rangelands: Building the Future. Proceedings VI International Rangeland Congress'. Townsville, 19-23 July. (Eds D. Eldridge and D. Freudenberger.) pp. 777-778. (VI International Rangeland Congress Inc., Townsville, Qld.)

Wallace, J. F., and Campbell, N. A. (1998). Evaluation of the feasibility of remote sensing for monitoring national state of the environment indicators. Australia: State of the Environment Technical Paper Series (Environmental Indicators), Department of the Environment, Canberra.

Wallace, J. F., Holm, A. McR., Novelly, P. E., and Campbell, N. A. (1994). Assessment and monitoring of rangeland vegetation composition using multi-temporal Landsat data. In: 'Proceedings 7th Australasian Remote Sensing Conference'. Melbourne Marine, 1994. pp. 1102-1109. (Remote Sensing and Photogrammetry Association of Australasia: Melbourne.)

Washington-Allen, R. A., West, N. E., Ramsey, R. D., and Efroymson, R. A. (2006). A protocol for retrospective remote sensing-based ecological monitoring of rangelands. Rangeland Ecology and Management 59, 19-29. 
Watson, I. W., Thomas, P. W. E., and Fletcher, W. J. (2007). The first assessment, using a rangeland monitoring system, of change in shrub and tree populations across the arid shrublands of Western Australia. The Rangeland Journal 29, 25-37. doi: 10.1071/RJ07018

West, N. E. (2003). History of rangeland monitoring in the U.S.A. Arid Land Research and Management 17, 495-545. doi: 10.1080/713936110

Wheaton, T. (1994). 'Plants of the northern Australian rangelands.' (Northern Territory Government, Department of Land, Housing and Local Government.)
Williams, D. L., Goward, S., and Arvidson, T. (2006). Landsat: yesterday, today and tomorrow. Photogrammetric Engineering and Remote Sensing 72, 1171-1178.

Witte, C., van den Berg, D., Rowland, T., O’Donnell, T., Denham, R., Pitt, G., and Simpson, J. (2006). Mapping Land Use in Queensland - Technical Report on the 1999 Land Use Map for Queensland. Department of Natural Resources, Mines and Water, Brisbane.

Manuscript received 4 November 2008; accepted 10 February 2009 